\title{
手性磷-烯配体在不对称催化领域的研究进展
}

\author{
于月娜＼cjkstart徐明华* \\ (中国科学院上海药物研究所 新药研究国家重点实验室 上海 201203)
}

\begin{abstract}
摘要 手性磷-烯配体在不对称催化反应中的应用近年来受到化学家们的关注, 已经成为一个热门的研究领域. 磷-烯 配体作为一类新兴杂化烯烃配体, 将具有强配位能力的磷原子与配位方式特殊但配位能力相对较弱的碳-碳双键结合 在一起, 兼具了部分手性膦配体和手性双烯配体的优点, 在一些过渡金属如䦅、钯、铱等催化的不对称反应中表现出 独特的催化性能, 不但能高效催化反应, 而且能取得优异的对映选择性. 本文综述了自 2004 年首例磷-烯配体的合成 及应用报道以来该领域的研究进展, 对过去十几年中发展的各种手性磷-烯配体的结构特征、合成方法以及它们在不同 催化不对称反应中的应用进行了分类概括，期望为未来进一步拓展手性烯烃配体的类型和应用提供思考和方向.
\end{abstract}

关键词 不对称催化; 手性配体; 烯烃配体; 磷-烯配体; 不对称合成

\section{Chiral Phosphorus-Olefin Ligands for Asymmetric Catalysis}

\author{
$\mathrm{Yu}$, Yue-Na $\quad \mathrm{Xu}$, Ming-Hua*
}

(State Key Laboratory of Drug Research, Shanghai Institute of Materia Medica, Chinese Academy of Sciences, Shanghai 201203, China)

\begin{abstract}
Transition-metal-catalyzed asymmetric transformations are among the most powerful and straightforward strategies to access various enantioenriched compounds. Hence, considerable efforts have been focused on the development of novel chiral ligands capable of highly efficient and enantioselective catalysis. The importance of olefin as ligand in transition-metal-catalyzed reactions wasn't realized until the report of the Zeise' salt in 1827. Nevertheless, application of chiral olefins as ligands for asymmetric catalysis has been overlooked for quite a long time owing to their relatively weak binding affinity toward the central metal. Since the groundbreaking work of Hayashi and Carreira in 2003 2004, chiral dienes as steering ligands in asymmetric catalysis have emerged as a fascinating new field. Given the weak coordination ability of olefins to transition-metals, functional groups with high coordination ability were considered to incorporate into the olefin framework to create a new type of hybrid olefin ligands for asymmetric catalysis. Over the past few years, a diverse range of hybrid olefin ligands were developed for various enantioselective transformations. Among these, phosphorus-based olefins represent a particularly interesting class of ligands since the first concept demonstration by Grützmacher in 2004, combining the strong coordinating phosphorus atom and the weak coordinating olefin into one ligand molecule. Typically, three structurally different types of phosphorus-based olefins are known in the literature, including phosphine-olefins, phosphoramidite/phosphinamidite-olefins, and phosphite/phosphinite-olefins. They have been successfully utilized in a series of transition-metal-catalyzed asymmetric reactions, such as iridium-catalyzed asymmetric hydrogenation of imines, allylic substitution; rhodium-catalyzed conjugate addition of organoboron reagents to $\alpha, \beta$-unsaturated compounds, 1,2-addition of organoboron reagents to imines/carbonyl compounds, intramolecular hydroacylation; and palladium-catalyzed asymmetric allylic alkylation/amination/etherification of allylic esters, as well as Suzuki-coupling reactions. In many cases, the reactions occur with high enantioselectivities, allows for access to a broad range of valuable chiral products. This paper reviews the literatures in this field and summarizes the remarkable progress and advances in the use of various P-olefins as powerful ligands for diverse transition metal-catalyzed asymmetric transformations since 2004. The aim is to offer an overview of the recent achievements in the rational design and development of new hybrid chiral olefin ligands for effective enantioselective catalysis. We hope that the current success of chiral phosphorus-olefin catalysis would provide an exciting opportunity for future exploration of chiral olefin ligands in a wide variety of asymmetric reactions.
\end{abstract}

Keywords asymmetric catalysis; chiral ligand; olefin ligand; phosphorus-olefin ligand; asymmetric synthesis

\section{1 引言}

过渡金属参与的不对称催化反应中, 手性配体是催 化剂产生不对称诱导和立体控制的源泉, 其对反应的催
化活性与对映选择性起着决定性作用，因此设计和合成 新型高效的手性配体一直是不对称催化领域非常重要 又极具挑战的研究课题 ${ }^{[1]}$.

* E-mail: xumh@simm.ac.cn

Received April 20, 2017; published May 12, 2017.

Project supported by the National Natural Science Foundation of China (Nos. 21325209, 21472205) and the Program of Shanghai Academic Research Leaders (No. 14XD1404400).

项目受国家自然科学基金(Nos. 21325209, 21472205)和上海市优秀学术带头人计划(No. 14XD1404400)资助. 
1827 年, Zeise ${ }^{[2]}$ 报道了第一例烯烃-金属络合物, 即 Zeise 盐 $\mathrm{K}\left[\mathrm{PtCl}_{3} \mathrm{C}_{2} \mathrm{H}_{4}\right]$. 自此之后, 人们开始认识到烯烃 可以与过渡金属进行配位, 但是烯烃作为手性配体的研 究一直处于空白. 2003 2004 年期间, Hayashi ${ }^{[3]}$ 和 Carreira $^{[4]}$ 两个课题组率先在这方面取得突破, 他们分别 成功设计、合成了含有手性桥环骨架的双烯配体并应用 于铑催化的芳基硼酸对 $\alpha, \beta$-不饱和酮的高对映选择性加 成及铱催化的不对称烯丙基化动力学拆分中. 在 Hayashi 和 Carreira 的开创性工作之后, 许多手性烯烃配 体相继被设计合成并广泛地应用于过渡金属催化的不 对称反应中 ${ }^{[5]}$, 其中若干代表性手性双烯配体如图式 1 所示.

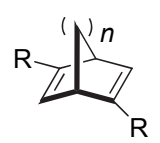

$n=1,2$

Hayashi, 2003

Hayashi, 2004

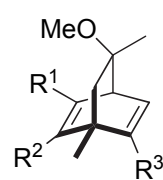

$\mathrm{R}^{3}$

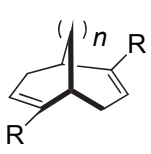

$n=1,2$

Carreira, 2004 Hayashi, 2005

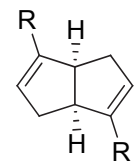

Lin and $\mathrm{Xu}, 2007$ Laschat, 2007

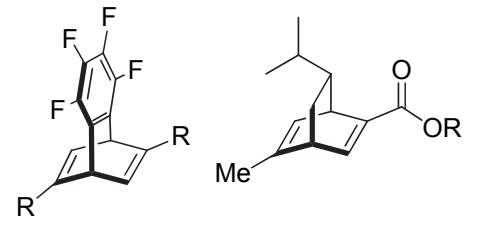

Hayashi, 2008

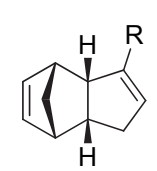

Lin, 2010
Hayashi, 2008

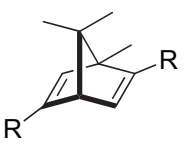

Wu, 2011

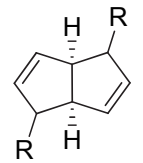

Lin and $\mathrm{Xu}, 2008$

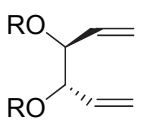

Du, 2009
图式 1 代表性手性双烯配体

Scheme 1 Representative chiral diene ligands

虽然手性双烯配体在一系列不对称催化反应中表 现出极其优秀的催化活性和对映选择性, 但鉴于双键与 过渡金属相对较弱的配位能力，在一定程度上也限制了 它们在更多反应中的应用. 为了增强手性烯烃配体的配 位能力, 有机化学家将配位能力强的官能团引入到烯烃 配体的分子骨架中, 发展了一系列杂化烯烃配体, 磷烯配体即是其中一类. Grützmacher 小组 ${ }^{[6 a]}$ 在 2004 年报 道了首例磷-烯配体及其应用, 从而开启了手性磷-烯配 体用于不对称催化研究的篇章. 磷-烯配体作为一类新 兴配体, 将具有强配位能力的磷原子与配位能力相对较 弱的碳碳双键结合在一起, 因此兼具了部分手性膦配体 和双烯配体的优点, 在过渡金属催化的不对称反应中往 往表现出独特的催化性能. 本文综述了过去十几年中发 展的手性磷-烯配体的合成方法以及它们在不对称催化 反应中的应用.

\section{2 磷-烯配体的合成}

近年来，多种结构类型的手性磷-烯配体被相继报 道, 如图式 2 所示, 这些磷-烯配体大都通过复杂的碳手 性骨架(如包含轴手性、平面手性、螺旋手性或多个中 心手性)将磷原子与配位双键结合. 在早期代表性的配 体中，通常以嵌入分子骨架中的烯烃作为配位单元，而 随着化学家们对配体设计研究的深入，一些结构相对简 单、合成方便的、双键在分子一端的、开链结构的磷烯配体被发现在不对称催化反应中也有很优秀的表现. 根据与磷原子相连元素的种类不同，本文中将手性磷烯配体大致分为膦-烯烃、亚磷/膦酰胺-烯烃和亚磷/膦 酸酯-烯烃配体三类进行讨论.<smiles>CC1CCC(C(C)C)C(OC2=Cc3ccccc3C(c3ccccc3)c3ccccc32)C1</smiles>

Grützmacher, 2004

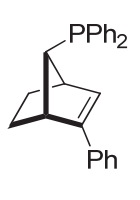

Hayashi, 2005

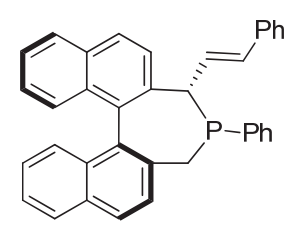

Widhalm, 2006

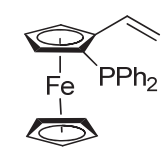

Císařová, 2006

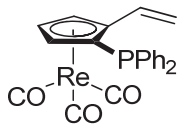

Bolm, 2007

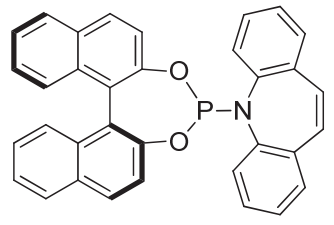

Carreira, 2007<smiles>C[C@H]1C=C[C@@H](OP)[C@@H](COP)O1</smiles>

Boysen, 2009<smiles>C=C[C@H]1OC(C)(C)O[C@@H]1C[18O]</smiles>

Du, 2010<smiles>CCCOC(=O)N1CC=CC1CPc1ccccc1</smiles>

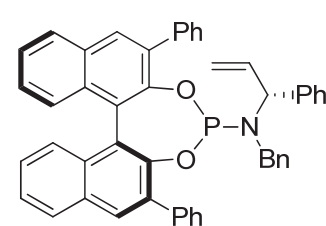

Du, 2011

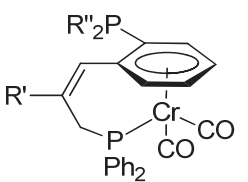

Kamikawa \& Ogasawara, 2012

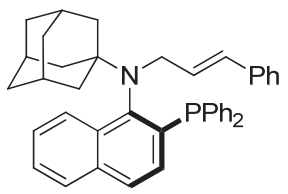

Mino, 2016

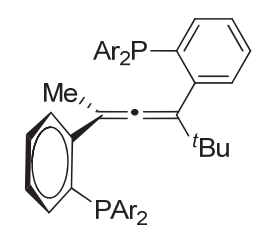

Ready, 2011

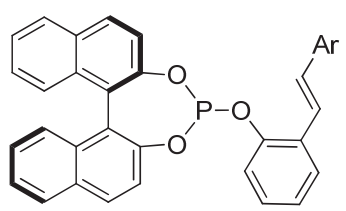

$\mathrm{Xu}, 2014$

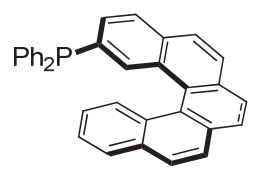

Suemune \& Usui, 2016

图式 2 代表性手性磷-烯配体

Scheme 2 Representative chiral P/olefin ligands 


\section{1 膦-烯烃配体}

2004 年, 德国的 Grützmacher 小组 ${ }^{[6 a]}$ 设计报道了第 一例基于二苯并庚烯骨架的手性膦烯配体 L1a. L1a 的 合成步骤包括六步, 以溴代烯烃 1 为起始原料, 与光学 活性的薄荷醇钾反应, 然后经过 $\mathrm{NaBH}_{4}$ 还原、氯代后得 到化合物 $\mathbf{2}$, 化合物 $\mathbf{2}$ 与二苯基膦反应生成膦化合物 $\mathbf{3}$, 两个非对映异构体可以通过硅胶柱分离得到. 但是由于 三价磷容易被氧化, 在硅胶柱分离之前必须先将磷用硣 烷进行保护. 最终所得配体与 $\left[\operatorname{Ir}(\operatorname{cod})_{2}\right] \mathrm{SO}_{3} \mathrm{CF}_{3}$ 反应制备 成络合物, 通过相应的络合物单晶衍射证实了烯烃双键 和磷原子同时与金属铱配位(如图式 3 所示).<smiles>O=c1c2ccccc2cc(Br)c2ccccc12</smiles>

1

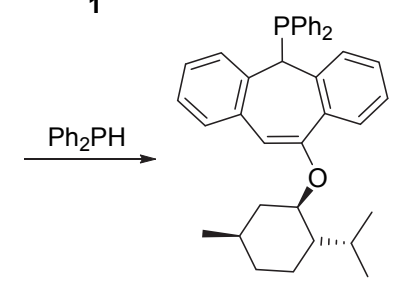

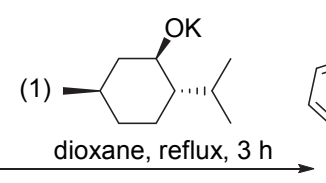

(2) $\mathrm{NaBH}_{4}, \mathrm{NaOH}, \mathrm{MeOH}$ (3) $\mathrm{SOCl}_{2}$, toluene

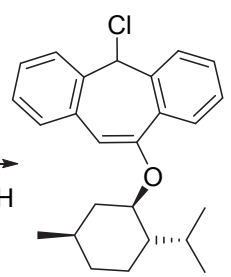

2
(1) $\mathrm{BH}_{3} \cdot \mathrm{SMe}_{2}$, toluene (2) chromatography, $\mathrm{SiO}_{2}$

(3)<smiles>C1COCCN1</smiles>

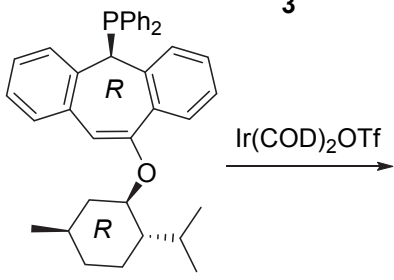

$(R, R)-\mathbf{L} 1 \mathbf{a}$

图式 3 手性膦烯配体 L1a 的合成

Scheme 3 Synthesis of chiral phosphine-olefin ligand L1a

随后, Grützmacher 小组 ${ }^{[7]}$ 对配体 L1a 的结构进行了 简化, 用苯基替代手性环状烷氧基, 合成了衍生配体 L1b. 膦烯配体 L1b 的合成一共需要 4 步，最初的原料 4 经过 Suzuki 偶联, Arbuzov 重排, HPLC 拆分和硅烷还原 得到目标产物, 虽然最后的总收率有 $85 \%$, 但是分子骨 架中的手性仍然是通过手性 HPLC 拆分构建起来的(如 图式 4 所示).

2005 年, Hayashi 小组 ${ }^{[8 \mathrm{a}]}$ 基于他们发展的双环[2.2.1] 庚二烯类双烯配体结构设计合成了含相同桥环骨架的 手性膦烯配体 $\mathbf{L 2}$, 以消旋的醇 7 为起始原料, 经过 Swern 氧化得到酩, 然后将羰基用缩醛保护. 叔丁基锂 拔溴, 再与 $\mathrm{ClPPh}_{2}$ 反应并且经过氧化得到了化合物 $\mathbf{9}$, 接下来用手性 HPLC 拆分, 脱除保护基得到光学活性 的、7 位为 $S$ 构型的酮 $\mathbf{1 0}$; 化合物 10 烯醇化后接着转化 成三氟甲磺酸酯, 再与格氏试剂进行偶联, 最后用 $\mathrm{HSiCl}_{3}$ 还原得到配体 $\mathbf{L 2}$, 总收率为 $36 \%$ (如图式 5 所示).<smiles>OC1c2ccccc2C=C(Br)c2ccccc21</smiles>

4

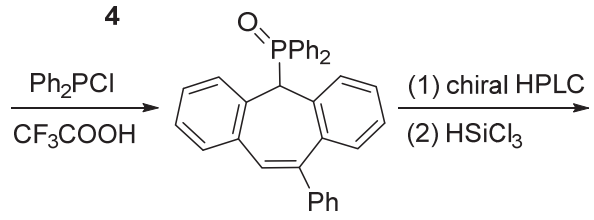

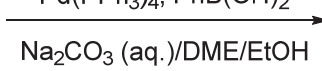<smiles>OC1c2ccccc2C=C(c2ccccc2)c2ccccc21</smiles>

$\mathrm{Ph}$

6<smiles>PC1c2ccccc2C=C(c2ccccc2)c2ccccc21</smiles>

L1b
图式 4 手性膦烯配体 L1b 的合成

Scheme 4 Synthesis of chiral phosphine-olefin ligand L1b
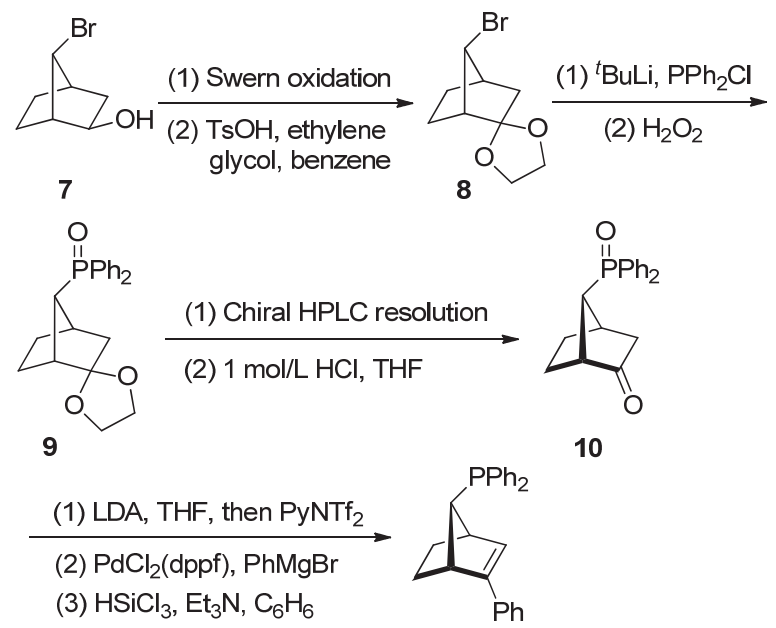

L2

图式 5 手性膦烯配体 $\mathbf{L 2}$ 的合成

Scheme 5 Synthesis of chiral phosphine-olefin ligand L2

2006 年, Widhalm 小组 ${ }^{[9]}$ 报道了配体 $\mathbf{L 3}$ 的合成及应 用. 配体的合成步骤比较长, 首先以 BINOL 为起始原 料，制备双三氟甲烷磺酸酯，再经过 Kumada 偶联得到 11; 化合物 11 经正丁基锂拔氢后与 $\mathrm{PPhCl}_{2}$ 反应得到 12. 同样由于三价磷容易被氧化, 所以用嗍烷保护, 13 经 BINOL 骨架诱导的不对称烯丙基取代反应得到 14, 最后脱除硼烷得到目标配体 $\mathbf{L 3}$ (如图式 6 所示).

2006, Císařová 小组 ${ }^{[10 a]}$ 从二茂铁醛出发, 利用手性 三醇进行诱导, 经多步反应制备了基于面手性二茂铁骨 架的开链膦烯配体 L4a, 并且验证配体的双键和磷原子 同时参与配位. 2007, Bolm 小组 ${ }^{[10 b]}$ 对配体 L4a 合成方法 进行优化，以 $(R)-(+)-N, N$-二甲基-1-二茂铁基乙胺(Ugi 胺)15 为起始原料, 首先通过手性胺诱导邻位拔氢, 然 后与 $\mathrm{PPh}_{2} \mathrm{Cl}$ 反应生成面手性的 16, 接下来再脱除氨基,

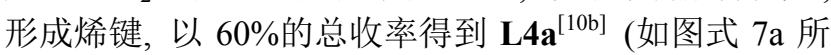
示). 2011 年, Císařová 小组 ${ }^{[10 c]}$ 在配体 $\mathbf{L 4 a}$ 的基础上进一 步合成了含有大环结构的手性膦烯配体 L4b(如图式 $7 b$ 所示). 


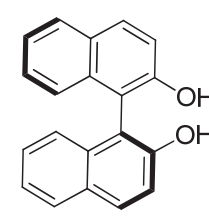

(1) $\mathrm{Tf}_{2} \mathrm{O} / \mathrm{PyH}$

(2) $\mathrm{NiCl}_{2}(\mathrm{dppp})$<smiles>Cc1ccc2ccccc2c1</smiles><smiles>Cc1cc2ccccc2cc1C</smiles>
(1) ${ }^{n} \mathrm{BuLi}$, TMEDA

(2) $\mathrm{CIPPh}_{2}$

(S)-BINOL
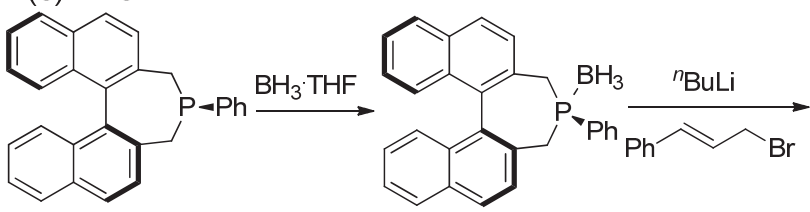

12

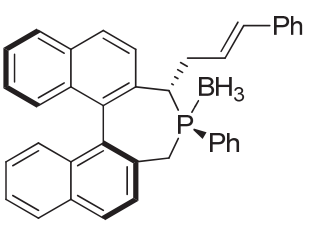

14

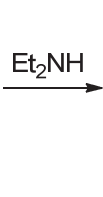

13

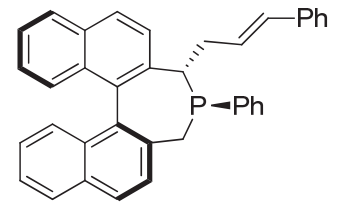

L3

图式 6 手性膦烯配体 $\mathbf{L 3}$ 的合成

Scheme 6 Synthesis of chiral phosphine-olefin ligand L3

a)

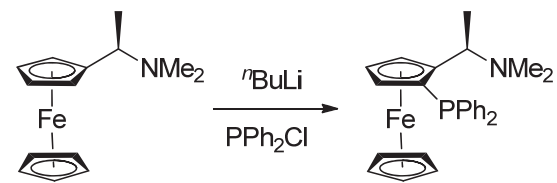

$(R)-15$

$(R, S p)-16$

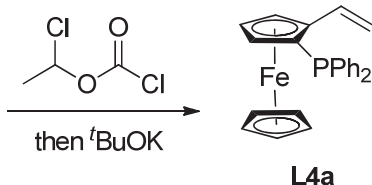

$60 \%$ yield for 2 steps

b)
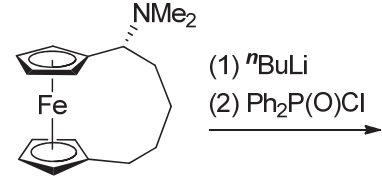

(1) ${ }^{n} \mathrm{BuLi}$

17
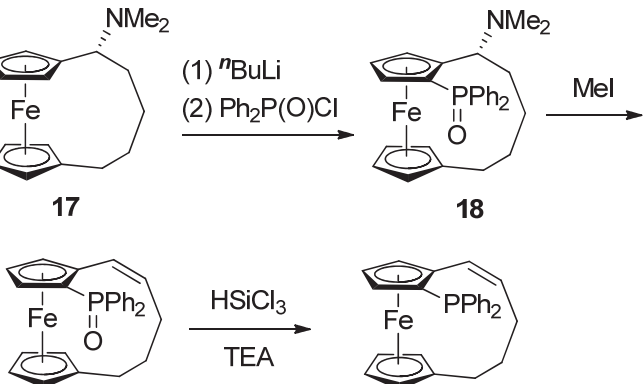

19

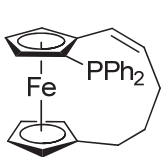

L4b
图式 7 手性膦烯配体 L4a 和 L4b 的合成

Scheme 7 Synthesis of chiral phosphine-olefin ligands L4a and L4b

为了考察手性络合物骨架中茂金属中心对配体催 化性能的影响, Bolm 等 ${ }^{[10 b]}$ 以手性络合物 20 为起始原料, 参照配体 L4a 的制备方法, 通过脱除氨基得到含有环戊 二烯-铼络合物骨架的膦烯配体 L4c (如图式 8 所示).

2010 年, 杜海峰小组 ${ }^{[11]}$ 将手性酒石酸酯骨架引入 到配体中，设计了结构简单的膦烯配体 L5. 参照已有文
献方法 ${ }^{[12]}, L-(+)$-酒石酸二乙酯 21 经六步反应转化为化 合物 22, 再对 22 进行亲核取代引入嗍烷保护的二芳基 膦基团，最后脱除保护基即得到所需配体 L5(如图式 9 所示).

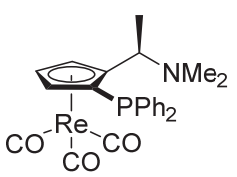

20

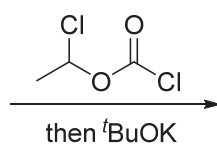

$\mathrm{CO}_{\mathrm{CO}}^{-\mathrm{Re}} \mathrm{CO}$

L4c

$46 \%$ yield
图式 8 手性膦烯配体 $\mathbf{L} 4 \mathrm{c}$ 的合成

Scheme 8 Synthesis of chiral phosphine-olefin ligand L4c
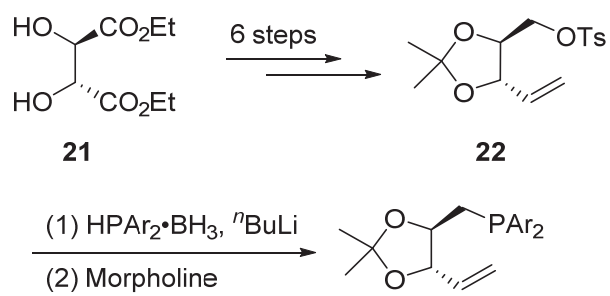

L5

图式 9 手性膦烯配体 $\mathbf{L 5}$ 的合成

Scheme 9 Synthesis of chiral phosphine-olefin ligand L5

杜海峰小组 ${ }^{[13 a]}$ 还以 $1,1^{\prime}$-联萗为手性骨架合成了具 有轴手性的开链膦烯配体 L6, 以 BINOL 为原料合成双 三氟甲磺酸酯，接下来在 $\mathrm{Pd}$ 催化下偶联引入一分子的 二苯基磷酰基得到化合物 23 , 化合物 23 在三氯硅烷条 件下还原，最后经过 Suzuki 偶联得到设计的配体 L6(如 图式 10 所示).

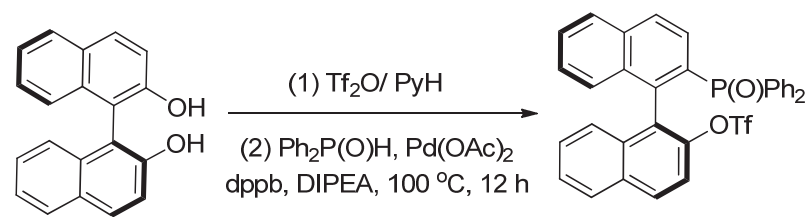

23<smiles>C=Cc1ccc2ccccc2c1-c1c(P)ccc2ccccc12</smiles>

L6

图式 10 手性膦烯配体 L6 的合成

Scheme 10 Synthesis of chiral phosphine-olefin ligand L6

2011 年, Ready 小组 ${ }^{[14 a]}$ 发展了一类含有联烯结构的 三齿膦烯配体 $\mathbf{L 7}$ ，首先参照已有方法合成化合物 $24^{[14 b]}$, 接着酰化得 25 , 再经烷基铜试剂炔丙基取代生 成联烯中间体 26, 化合物 26 经叔丁基锂拔溴引入膦单 元，最后重结晶得到光学纯配体 L7(如图式 11 所示). 
<smiles>[R9][C@@](C)(C#Cc1ccccc1Br)c1ccccc1B(OC)OC</smiles><smiles>CC(C)(C)C1CCCCC1</smiles>

24: $\mathrm{R}=\mathrm{H}$ 25: $R=O A C$

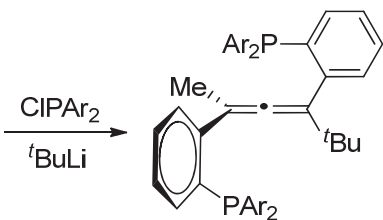

L7

$40 \%$ yield<smiles>Cc1cccc(S(=O)O)c1C=C(c1ccccc1Br)C(C)C</smiles>

26 $88 \%$ yield
图式 11 含联烯手性双膦配体 L7 的合成

Scheme 11 Synthesis of chiral allene-containing phosphine ligand L7

2012 年, Kamikawa 和 Ogasawara 小组 ${ }^{[15 a]}$ 通过手性 钼络合物催化分子内的不对称烯烃复分解，对消旋底物 $27 \mathbf{a}$ 进行动力学拆分, 构建了高光学纯度的面手性 $\pi$-芳 烃-铬络合物, 其中化合物(S)-28a 经过重结晶, ee 值由 97\%可以升至 $99.9 \%$, 在正丁基锂条件下锂化引入二苯 基膦基团，即可得到 $e e$ 值大于 $99.9 \%$ 的平面手性二羰基 铬络合物骨架的膦烯配体 $(R)-\mathbf{L 8 a}$ (如图式 12 所示).

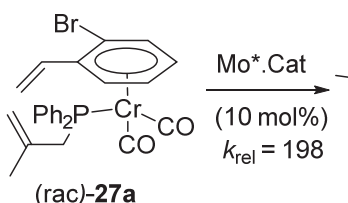

(rac)-27a

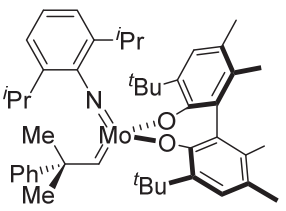

Mo*.Cat

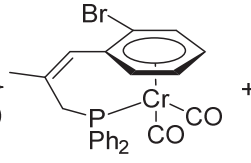

(S)-28a

(97\% ee, $47 \%$ yield)

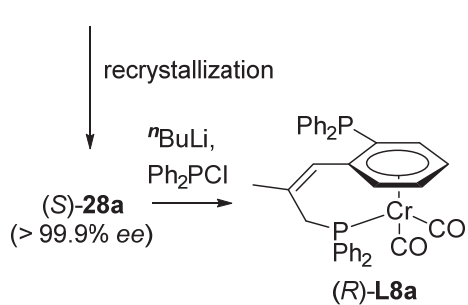

(>99.9\% ee, $74 \%$ yield)
图式 12 面手性膦烯配体 L8a 的合成

Scheme 12 Synthesis of planar-chiral phosphine-olefin ligand L8a

该路线由于采取动力学拆分, 所以收率最高也只能 达到 $50 \%$; 此外, 关环所用手性钿催化剂对氧气和水不 稳定，而且扩大反应规模时收率不理想. Ogasawara 小 组 ${ }^{[15 b]}$ 后续对路线进行了优化, 参照文献方法 ${ }^{[16]}$ 高效地 制备了光学纯的 $\pi$-芳烃-铬络合物 $(S)-29$, 从 $(S)$-29 出发, 通过 Wittig 反应生成含有末端双键的化合物 $(S)-30$, 经 配位交换，置换掉一个 $\mathrm{CO}$ 得到 $(S)$-27. 化合物(S)-27 在 Grubbs II 催化剂条件下进行烯烃复分解成环，最后引 入膦基团得到目标配体 $(R)-\mathbf{L 8}$ (如图式 13 所示).

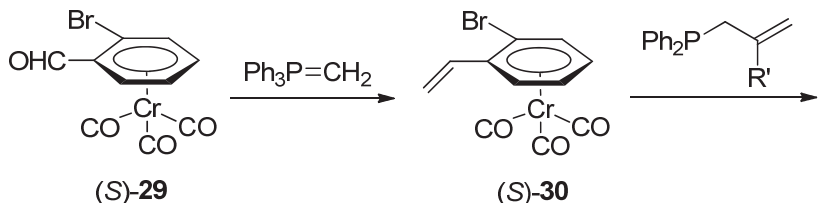

(S)-30

$(>99.9 \%$ ee)

$62 \%$ yield
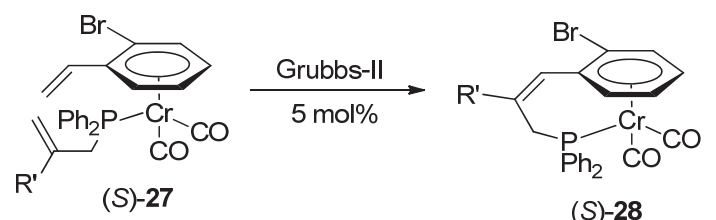

(S)-28

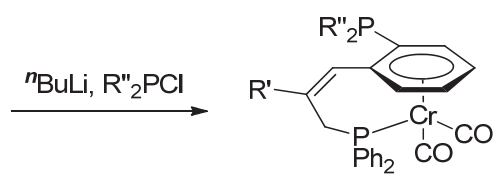

$(R)$-L8

$(>99.9 \%$ ee)

图式 13 配体 L8 合成路线的优化

Scheme 13 Optimization of synthetic route of ligand $\mathbf{L 8}$

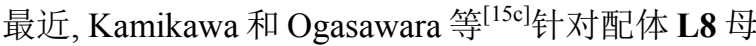
核 $\pi$-芳烃-铬不稳定的问题又对其进行了改造，根据等 电子原则, 引入了性质稳定的环戊二烯-锰结构, 制备 了一系 $\mathrm{CpMn}(\mathrm{I})$ 类膦烯配体 $\mathbf{L 9}$. 配体 $\mathbf{L 9} \mathbf{a}$ 的合成是以环 戊二烯三羰基锰为起始原料，根据文献报道方法 ${ }^{[17]}$ 制 备手性缩醛中间体 32, 后经叔丁基锂拔氢、澳代得到高 光学纯的中间体 $\mathbf{3 3}$; 化合物 $\mathbf{3 3}$ 水解后重结晶给出 $e e$ 值 大于 99.9\%的关键中间体 34; 中间体 34 通过 Wittig 烯 化、配体交换两步反应顺利转换为化合物 $\mathbf{3 5}$, 从化合物 35 到配体 L9a 的转化与配体 L8 的合成路线一致(如图 式 14 所示).

2014 年, Sieber 等 ${ }^{[18]}$ 报道了一类含有手性磷骨架的 杂化烯烃配体, 他们以手性母核 38 为起始原料, LDA 拔 氢后与芳丙烯基氯化物反应得到化合物 $\mathbf{4 0}$, 再经还原 脱氧即可得到配体 L10, 但 $\mathrm{Ar}$ 为缺电子芳基时, 需要先 制备中间体 39, 然后经烯烃复分解反应生成化合物 40(如图式 15 所示).

2015 年, Hayashi 小组 ${ }^{[19]}$ 以 $L$-羟脯氨酸为手性母核 发展了一类新型的膦烯配体. 首先参考文献方法 ${ }^{[20]}$ 将 $L$-羟脯氨酸转化为 $S$ 构型的醇, 然后将羟基转化为三氟 甲磺酸酯; $0{ }^{\circ} \mathrm{C}$ 下与 $\mathrm{KPPh}_{2}$ 反应引入二芳基膦, 经硼烷 保护分离得到化合物(S)-42, 42 在 DABCO 条件下方便 地脱除 $\mathrm{BH}_{3}$ 得到双键在环内的膦烯配体 $(S)$ - L11 (如图式 16 所示).

最近, Suemune 和 Usui 等 ${ }^{[21]}$ 成功发展了一类结构独 特的具有 7,8-二氢[5]螺烯和[5]螺烯母核的新型膦烯配 体 L12a 和 L12b, 其中芳香母核作为烯烃配体, 它们的 合成如图式 17 所示. 底物 $\mathbf{4 3}$ 和邻溴苯硼酸通过 Suzuki 偶联生成化合物 $\mathbf{4 5}$; 化合物 45 通过改良的 Seyferth-Gilbert 反应转化为端㶧, 端炔在氯化钯催化下 发生分子内的环化异构最后生成消旋[5]螺烯 46; 再经 
过三步转化引入二苯基氧膦生成 47; 消旋的 47 经动力 学拆分得到光学纯产物 $(P)-47$, 接着经 $\mathrm{HSiCl}_{3}$ 还原或氧 化脱氢、再还原脱氧后即得到目标配体 L12a 和 L12b.
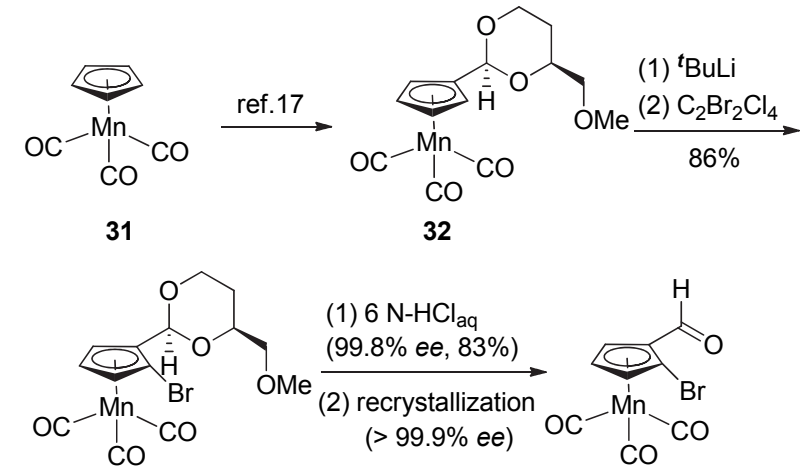

33

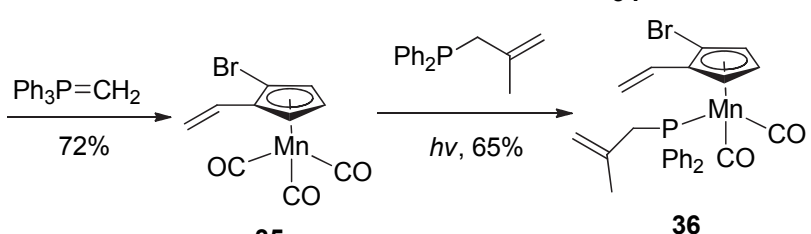

35

36

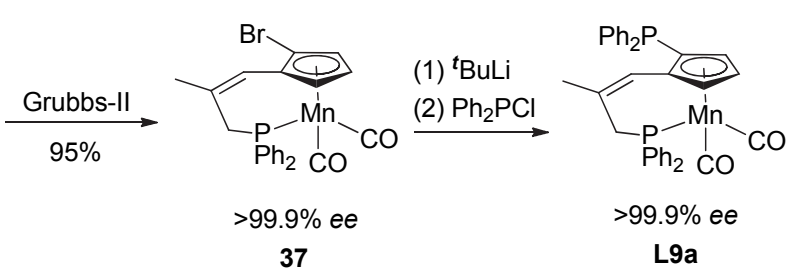

图式 14 手性膦烯配体 L9a 的合成

Scheme 14 Synthesis of planar-chiral phosphine-olefin ligand L9a

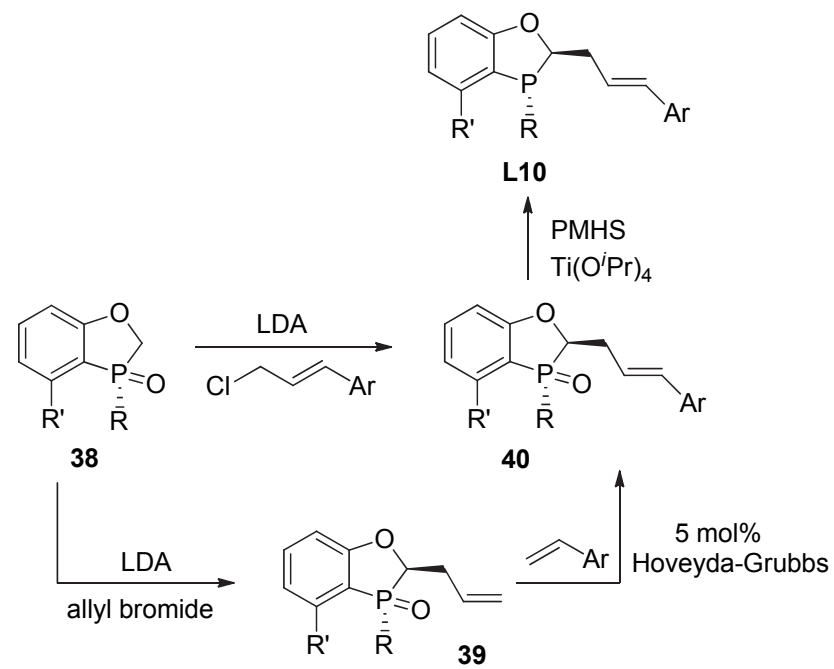

图式 15 手性膦烯配体 $\mathbf{L 1 0}$ 的合成

Scheme 15 Synthesis of chiral phosphine-olefin ligand L10

2016年 Mino 等 ${ }^{[22]}$ 还报道了一类具有轴手性的膦烯 配体 L13. 如图式 18 所示, 以化合物 49 为起始原料, 经 氮烷基化、还原脱氧两步反应就可以得到消旋的配体, 最后通过手性柱拆分得到两个阻转异构的配体.
$\mathrm{HO}$

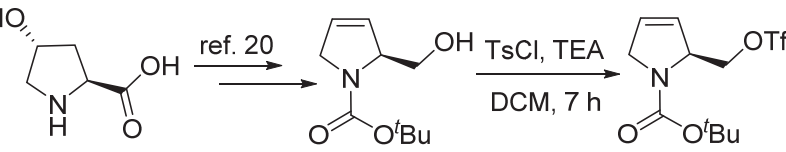

L-hydroxyproline

(S)-41

$92 \%$ yield

$\underset{\text { (2) } \mathrm{BH}_{3} \cdot \mathrm{SMe}_{3},}{\mathrm{O}^{\circ} \mathrm{C}, 0.5 \mathrm{~h}}$

(S)-42

(S)-L11

$55 \%$ yield for 2 steps

$80 \%$ yield

图式 16 手性膦烯配体 L11 的合成

Scheme 16 Synthesis of chiral phosphine-olefin ligand L11

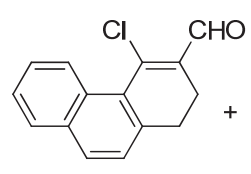

43

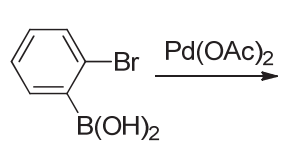

44

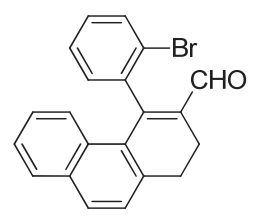

45

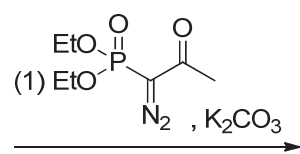

(2) $\mathrm{PdCl}_{2}$

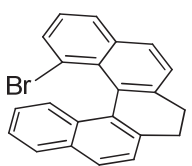

(1) ${ }^{n} \mathrm{BuLi}$

(2) $\mathrm{Ph}_{2} \mathrm{PCl}$

(3) $\mathrm{H}_{2} \mathrm{O}_{2}$

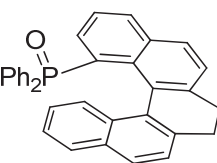

(1)

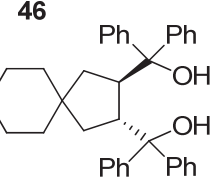

(2) column chromatography

(3) recrystallization

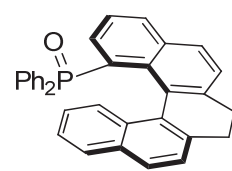
$\underset{\substack{\text { toluene/THF } \\ 100^{\circ} \mathrm{C}}}{\stackrel{\mathrm{HSiCl}_{3}, \mathrm{P}(\mathrm{OEt})_{3}}{\longrightarrow}}$

$(P)-47$

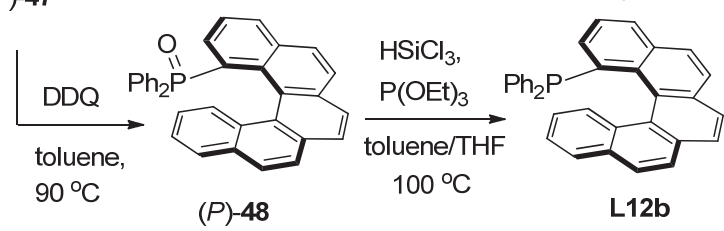

图式 17 螺旋手性膦配体 L12 的合成

Scheme 17 Synthesis of chiral helicenylphosphine ligand L12

\section{2 亚磷/膦酰胺-烯烃配体}

虽然配体 L2 在过渡金属铑催化的不对称反应中表 现出优异的催化活性，但是其结构相对复杂，合成步骤 长, 所以 Hayashi 小组 ${ }^{[23]}$ 在膦烯配体 $\mathbf{L 2}$ 的基础上对其进 行结构改造，保留对手性控制起决定性作用的双键，设 计合成了一类新骨架的亚膦酰胺-烯烃配体 L14. 配体 


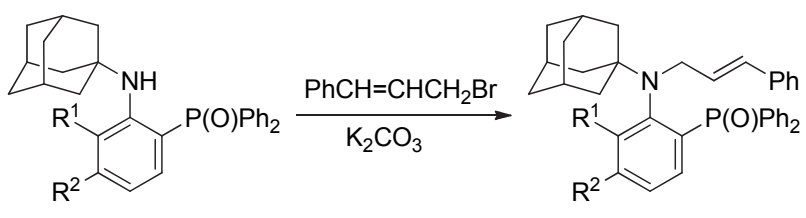

49

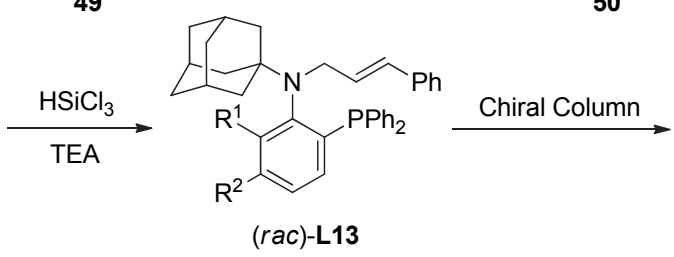

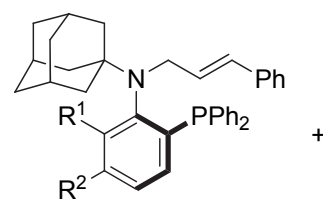

(R)-L13

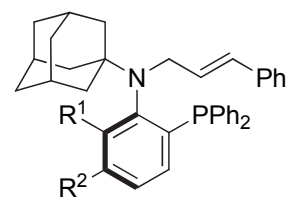

(S)-L13
图式 18 轴手性膦烯配体 L13 的合成

Scheme 18 Synthesis of axial-chiral phosphine-olefin ligand L13

的合成以光学活性的烯丙基胺 51 为起始原料, 先将 $\mathbf{5 1}$ 中的氨基进行烯丙基化，所得二烯丙基胺在 Grubbs 二 代催化剂作用下关环得到 53, 化合物 $\mathbf{5 3}$ 脱除 Boc 保护 基后再与二苯基氯化膦反应，在氨基上引入二苯基膦基 团得到配体 L14(如图式 19 所示).
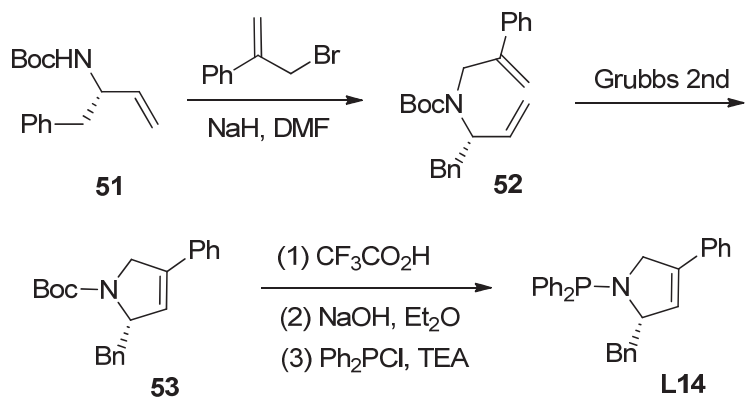

图式 19 手性亚膦酰胺-烯配体 L14 的合成

Scheme 19 Synthesis of chiral aminophosphinite-olefin ligand L14

2007 年, Carreira 小组 ${ }^{[24 a]}$ 设计合成了一类新型的基 于亚磷酰胺结构的杂化烯烃配体 L15a, 以光学纯的 $(S)$-BINOL 为起始原料, 首先与三氯化磷反应制备相应 的磷酰氯, 然后再与二苯并呋庚因反应得到目标产物 (如图式 20 所示). 值得一提的是该配体结构简单, 合成 简便，尤其是在很多不对称反应中都表现优异.

2011 年, 杜海峰小组 ${ }^{[25 a]}$ 在已有工作基础上, 将链 状烯烃与以 BINOL 为手性骨架的亚磷酰胺类结构结合, 合成了配体 L16a. 以 $(S)$-BINOL 为起始原料, 参照文献 方法, 经 4 步反应, 在 3,3'-位引入苯基, 然后与三氯化 磷反应制备相应的磷酰氯, 最后将手性胺与正丁基锂反 应制备相应的锂盐再与磷酰氯反应得到目标产物(如图 式 21 所示).

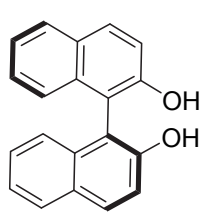

(S)-BINOL

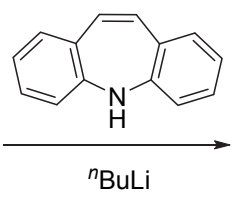

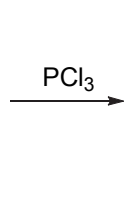

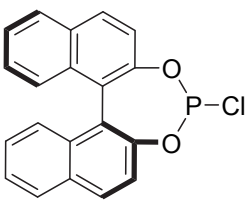

54

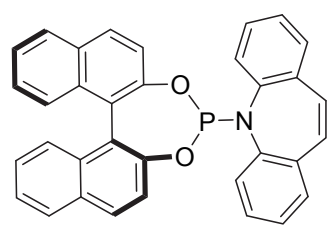

L15a
图式 20 手性亚膦酰胺-烯配体 L15a 的合成

Scheme 20 Synthesis of chiral phosphoramidite-olefin ligand L15a

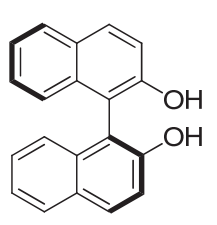

(S)-BINOL

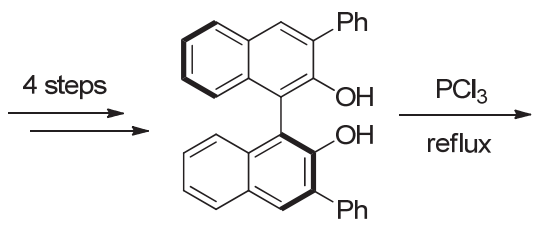

55<smiles></smiles>

56

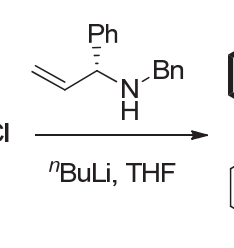

(che
图式 21 手性亚膦酰胺-烯配体 L16a 的合成

Scheme 21 Synthesis of chiral phosphoramidite-olefin ligand L16a

2016 年，陈谦等 ${ }^{[26]}$ 报道了一个脯氨酸衍生的亚膦 酰胺-烯烃配体 L17，其与 L11 的不同之处在于烯烃双键 由环内移到环外，将二芳基膦基团连接到吡咯烷氮上， 这样的设计使得配体合成更加简便. 如图式 22 所示，以 手性 2-吡咯烷甲醇为起始原料, 经氧化得到吡咯烷甲 醛, 然后进行 HWE 反应引入双键得到中间体 59; 接着 在酸性条件下脱除氮上的 Boc 保护基后与二苯基氯化 膦反应即可得到配体 L17.

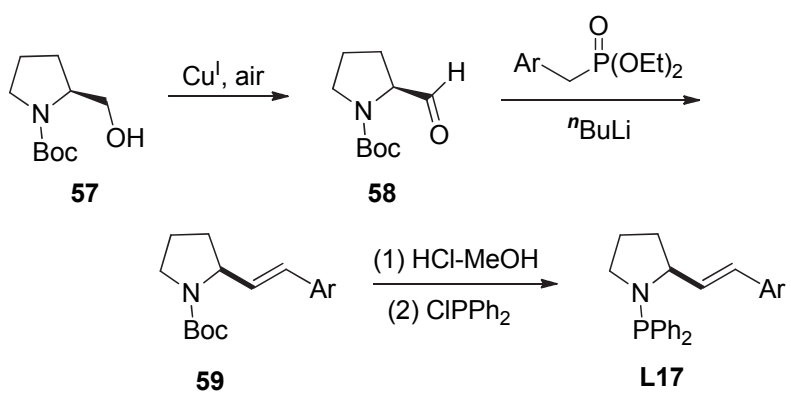

图式 22 手性亚膦酰胺-烯配体 L17 的合成

Scheme 22 Synthesis of chiral aminophosphinite-olefin ligand L17 


\section{3 亚磷/膦酸酯-烯烃配体}

2009 年, Boysen 小组 ${ }^{[27]}$ 设计了一类以亚膦酸酯为 配位单元的手性烯烃配体 $\mathbf{L 1 8}$, 其合成是以 $D$-葡萄糖衍 生物 60 为起始原料, 脱除乙酰基后将其中的伯羟基用 三苯基甲基保护, 剩余的羟基与二苯基氯化膦反应即得 到配体 L18(如图式 23 所示).

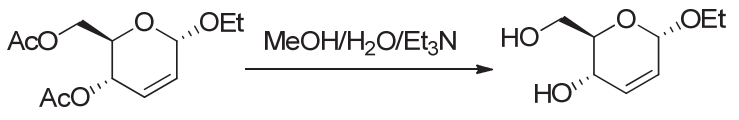

60

61

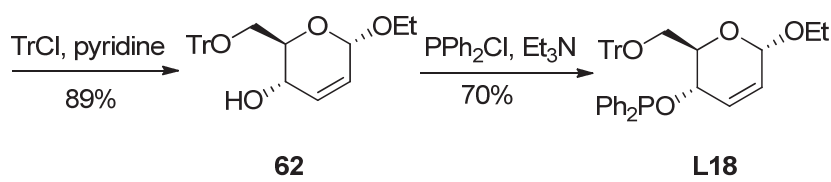

图式 23 手性亚膦酸酯-烯配体 L18 的合成

Scheme 23 Synthesis of chiral phosphinite-olefin ligand L18

2014 年，徐明华小组 ${ }^{[28 a]}$ 首次将方便易得的亚磷酸 三酯结构引入磷-烯配体的设计, 发展了基于轴手性 1,1'-联萗骨架的亚磷酸酯-烯烃配体 L19a. 从廉价易得 的水杨醛出发, 在叔丁醇钾/微波条件下, 与苠基亚磷酸 酯发生 Horner-Wadsworth-Emmons 反应, 得到反式邻苯 乙烯基苯酚, 接着在钠氢存在下, 加入 $(R)-\mathrm{BINOL}$ 与 $\mathrm{PCl}_{3}$ 反应得到的亚磷酰氯, 总计三步反应即可顺利得到 目标配体 L19a. 这类开链磷烯配体结构简单, 以轴手性 BINOL 骨架替代很多文献报道中复杂的碳手性骨架, 合成非常便捷(如图式 24 所示). 在后续研究中, 发现用 二面角更大的 $\mathrm{H}_{8}$-BINOL 作为手性骨架可以进一步提高 配体与铑配位后的催化剂的对映选择性.

\section{3 磷-烯配体在不对称催化中的应用}

高效合成光学纯手性化合物是现代化学领域中一 个最为活跃的研究热点和前沿. 通过手性催化剂进行不 对称催化是制备光学纯手性化合物最为有效的方法, 仅 使用少量手性源就能产生大量手性化合物, 并且可以通 过改变配体来改善催化剂的性能, 因此吸引了无数化学 家在这方面不断地进行研究与探索. 近些年发展的手性 磷-烯配体也被广泛地应用于过渡金属催化的各种反应 中, 如不对称氢化、共轭加成、亚胺/羰基化合物加成、 烯丙基取代、分子内加氢酰化、偶联等, 并在一些反应 中取得了非常优异的结果, 高效构建了一系列结构重要 的手性化合物.

\section{1 不对称氢化}

Grützmacher 小组 ${ }^{[6 a]}$ 最早将他们发展的手性膦烯配 体 L1a 用于金属 $\operatorname{Ir}$ 催化的亚胺及烯胺的不对称氢化反 应中. 如图式 25 所示, 在对亚胺的不对称氢化反应中,

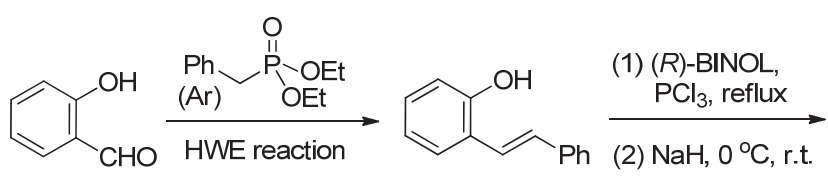

63

64

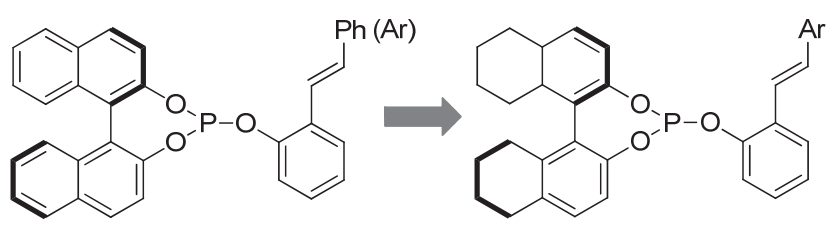

L19a

图式 24 手性亚膦酸三酯-烯配体 L19a 的合成 Scheme 24 Synthesis of chiral phosphite-olefin ligand L19a

产物的构型是由二苯并庚烯骨架中与磷相连碳的手性 所决定的, 但是 $\mathrm{R}$ 基团的手性对 $e e$ 值的高低有较大影 响; 在烯胺的不对称氢化反应中, 产物的构型则是由 $\mathrm{R}$ 基团的手性决定. 虽然反应仅取得了中等到良好的对映 选择性，这是第一例关于手性磷-烯配体在不对称催化 反应中的应用, 说明这类新型配体的设计理念是可行 的, 烯烃配体不但可用于催化, 甚至还能用于不对称氢 化反应, 这个工作为手性磷-烯配体的进一步研究和探 索打下了重要的基础.

\section{2 芳基硼酸对缺电子烯烃的不对称 1,4-加成}

有机嗍试剂对缺电子烯烃的不对称 1,4-加成反应是 一种高效构建手性化合物的方法, 近些年化学家发展了 各种各样的手性配体并成功用于此类反应中. 2006 年, Grützmacher 小组 ${ }^{[7]}$ 成功制备得到手性膦烯配体 L1b 与 金属铑的手性络合物，将其用于催化苯硼酸对环己烯酮 的共轭加成，以 $85 \%$ 的收率和高达 $95 \%$ 的对映选择性得 到目标产物. 随后, Hayashi $(\mathbf{L 2}, \mathbf{L 1 1})^{[8,19]}$ 、Widhalm $(\mathbf{L 3})^{[9]} 、$ Císařová 和 Bolm $(\mathbf{L 4})^{[10]}$ 、Dorta $(\mathbf{L 1 5 a})^{[29]}$ 、Boysen $(\mathbf{L 1 8})^{[27]}$ 、Kamikawa 和 Ogasawara $(\mathbf{L 8}, \mathbf{L 9})^{[15]}$ 以及陈 $(\mathbf{L 1 7})^{[26]}$ 等小组都将设计合成的一系列新型磷-烯配体用 于铑催化的芳基硼酸对环状 $\alpha, \beta$-不饱和酮的不对称共轭 加成反应中, 大多取得了比较理想的结果(以苯硼酸加 成为例, 部分结果概括如图式 26 所示), 但基于面手性 的二茂铁骨架的膦烯配体 L4a 立体控制不尽理想，只能 得到 53\%的 $e e$ 值, 双键嵌入环内后的配体 L $4 \mathbf{b}$ 取得的 对映选择性有所提高. 有意思的是, 手性茂类络合物骨 架中金属中心对配体催化性能确实有一定的影响, 相比 L4a，铼-环戍二烯络合物配体 L4c 能取得 71\%的对映选 择性. 尤其值得一提的是，平面手性二羰基铬或锰络合 物骨架的膦烯配体 L8, L9 在反应中表现优异, 几乎都 以定量收率获得光学纯的产物, 但在催化剂用量方面则 相比较大多数其它配体 (3 mol\%) 要高, 通常需要 5 $\mathrm{mol} \%$ 的 $[\mathrm{Rh}]$ 和 $5.2 \mathrm{~mol} \%$ 的手性配体. 


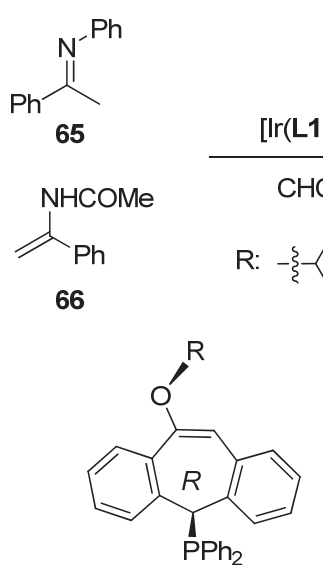

$(R, R)-\mathbf{L} \mathbf{1 a}$
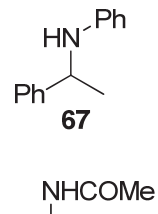

$\overbrace{\mathrm{Ph}}$

68
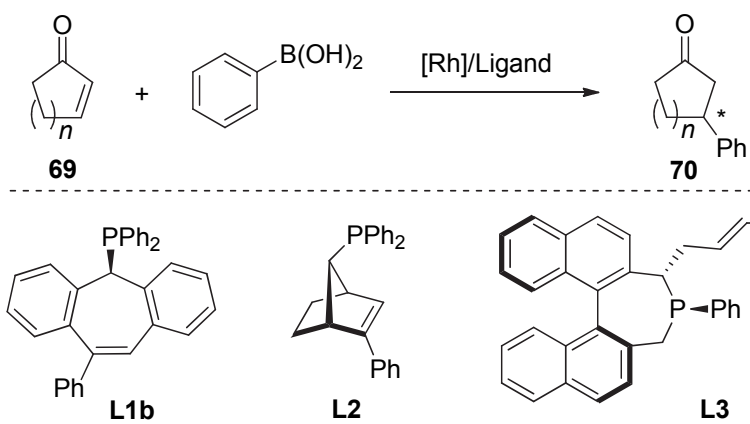

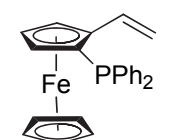

L4a

$n=2,96 \%$ yield, $53 \%$ ee

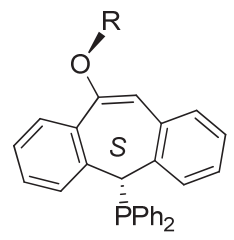

$(R, S)-\mathbf{L} \mathbf{1 a}$
(S, S)-L1a

$98 \%$ yield, $86 \%$ ee $(R) \quad 98 \%$ yield, $45 \%$ ee $(R)$

图式 $25 \mathrm{Ir} / \mathrm{L1a}$ 催化的不对称氢化

Scheme 25 Ir/L1a-catalyzed asymmetric hydrogenation

磷-烯配体与金属铑形成的络合物同样可以顺利催 化芳基硼酸对环状 $\alpha, \beta$-不饱和内酯(图式 27)和马来酰胺 (图式 28)的不对称共轭加成, 反应取得了良好到优秀的 对映选择性.

链状 $\alpha, \beta$-不饱和酮相较于环状不饱和酮其本身柔性 更大, 所以实现这类化合物的高立体选择性加成是极具 挑战的. 磷-烯配体 L2、L8、L9、L17 和 L18 与铑形成 的络合物可以顺利催化苯硼酸对底物 75 的共轭加成. 其中配体 $\mathbf{L 2}$ 给出了 $72 \%$ 的 $e e$ 值; 配体 $\mathbf{L 1 8}$ 虽然收率比 较理想, 但 $e e$ 值仅有 $52 \%$; 配体 $\mathbf{L 9}$ 相对于 $\mathbf{L 8}$ 效果明 显改善(如图式 29 所示).

手性磺酸酯类化合物在药物研究中具有重要价值. 徐明华小组 ${ }^{[28 b]}$ 将发展的具有手性 1,1'-联-2-菜酚骨架的 开链亚磷酸酯-烯烃配体 L19b 用于铑催化的芳基硼酸对 $\alpha, \beta$-不饱和磺酸酯的不对称 1,4-加成反应中, 发现该类 磷-烯配体与 $\mathrm{Rh}(\mathrm{I})$ 形成的催化剂展现出极高的催化活性 和对映选择性, 反应可以在温和条件下进行, 产物最高 能取得 99\%ee(如图式 30 所示). 该催化体系简单实用, 底物普适性广, 为合成偕二芳基取代的手性磺酸酯类化 合物提供了一个有用的新方法.

此外，配体 $\mathbf{L 1 7}$ 和铑的络合物还被用于催化对甲氧 基苯硼酸与肉桂酸甲酯 $(95 \%$ yield, $92 \% e e$ ) 以及硝基苯 乙烯 $(79 \%$ yield, $30 \% e e)$ 的不对称 1,4-加成反应中 ${ }^{[26]}$.

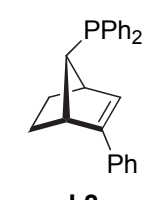

L2

$n=2,85 \%$ yield, $95 \%$ ee

$n=1,91 \%$ yield,

$98 \%$ ee $n=2,94 \%$ yield, $93 \%$ ee

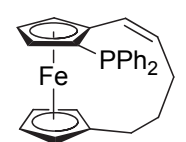

L4b

$n=1,81 \%$ yield, $88 \%$ ee $n=2,77 \%$ yield, $86 \%$ ee

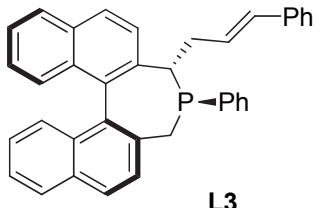

L3

$n=1,70 \%$ yield, $88 \%$ ee $n=2,88 \%$ yield, $98 \%$ ee $n=3,70 \%$ yield, $91 \%$ ee $n=3,80 \%$ yield, $90 \%$ ee

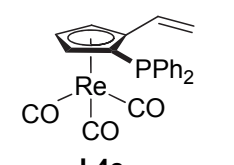

L4C

$n=2,86 \%$ yield, $71 \%$ ee

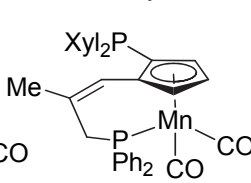<smiles></smiles>

L8a

L9b

L15a

$n=1,95 \%$ yield, $\quad n=1,99 \%$ yield, $99.6 \%$ ee $99.9 \%$ ee $n=2,99 \%$ yield, $99.9 \%$ ee $n=2,98 \%$ yield, $99.5 \%$ ee

$\left(\mathrm{o}-\mathrm{TolB}(\mathrm{OH})_{2}\right)$

$n=1,95 \%$ yield $65 \%$ ee<smiles>CCO[C@@H]1C=C[C@@H](OP)[C@@H](CO[Te])O1</smiles>

L18

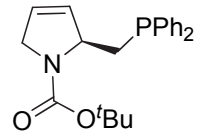

L11 $n=2,90 \%$ yield $92 \%$ ee

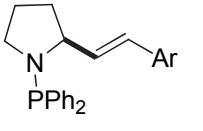

L17 $n=1,82 \%$ yield, $99 \%$ ee $n=2,99 \%$ yield, $n=1,95 \%$ yield, $86 \%$ ee $n=2,80 \%$ yield, $99 \%$ ee $\quad 98 \%$ ee $\quad n=2,97 \%$ yield, $93 \%$ ee

图式 26 铑催化的环状 $\alpha, \beta$-不饱和酮的不对称 1,4-加成

Scheme 26 Rh-catalyzed asymmetric 1,4-addition of $\alpha, \beta$-unsaturated cyclic ketones<smiles>CC(C)C1C=CC(=O)CC1</smiles><smiles>Pc1cccc(P)c1</smiles>

L2

$89 \%$ yield, $97 \%$ ee $\mathrm{Ph}_{2} \mathrm{P}$

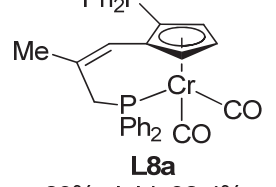

$72 \%$ yield, $90 \%$ ee $56 \%$ yield, $62 \%$ ee
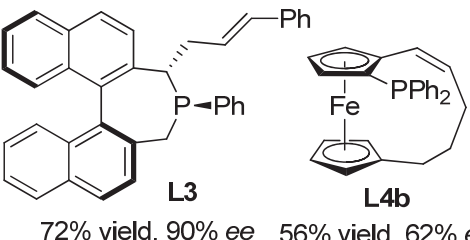

L4b

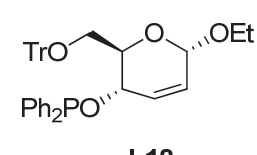

L18

$89 \%$ yield, $99.4 \%$ ee $\quad 48 \%$ yield, $94 \%$ ee

图式 27 铑催化的不饱和内脂的不对称 1,4-加成

Scheme 27 Rh-catalyzed asymmetric 1,4-addition of $\alpha, \beta$-unsaturated lactone 

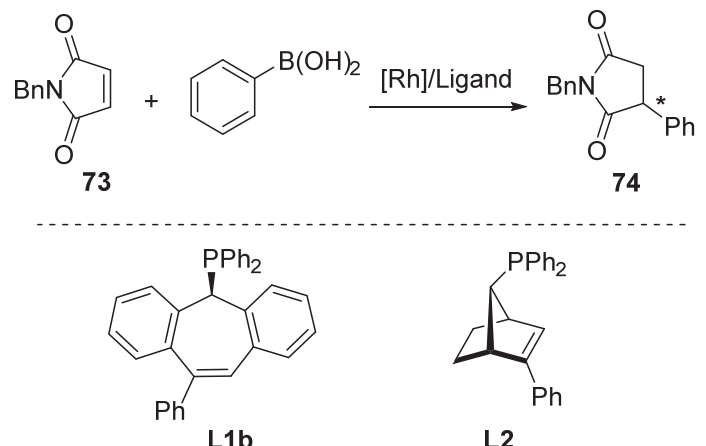

L2

$98 \%$ yield, $80 \%$ ee

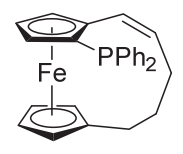

L4b

$65 \%$ yield, $26 \%$ ee
$98 \%$ yield, $93 \%$ ee

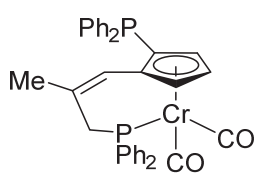

L8a

$85 \%$ yield, $81 \%$ ee

图式 28 铑催化的马来酰胺的不对称 1,4-加成

Scheme 28 Rh-catalyzed asymmetric 1,4-addition of maleimide

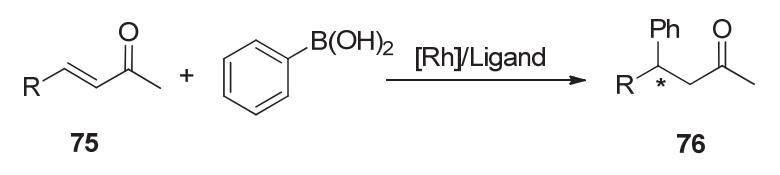

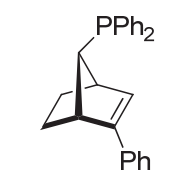

L2

$\mathrm{R}={ }^{n}$ Pent $91 \%$ yield, $72 \%$ ee

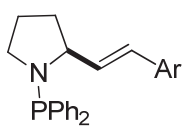

L17

$\mathrm{R}=\mathrm{Ph}$

$73 \%$ yield, $87 \%$ ee 4- $\mathrm{MeOC}_{6} \mathrm{H}_{4} \mathrm{~B}(\mathrm{OH})_{2}$

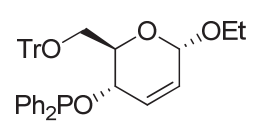

$\mathrm{R}=\mathrm{Me}$

$90 \%$ yield, $52 \%$ ee

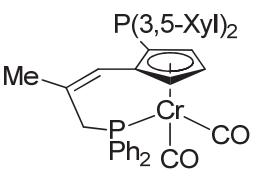

L8b

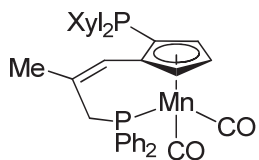

L9b

$\mathrm{R}=\mathrm{Me}: 34 \%$ yield, $88 \%$ ee

$\mathrm{R}={ }^{n}$ Pent: $43 \%$ yield, $88 \%$ ee
$\mathrm{R}=\mathrm{Me}: 99 \%$ yield, $98 \%$ ee $\mathrm{R}={ }^{n}$ Pent: $77 \%$ yield, $99.8 \%$ ee

图式 29 铑催化的链状 $\alpha, \beta$-不饱和酮的不对称 1,4-加成

Scheme 29 Rh-catalyzed asymmetric 1,4-addition of $\alpha, \beta$-unsaturated acyclic ketones

\section{3 有机硼酸对 $C=X(X=N, O)$ 双键的不对称 1,2-加 成}

2014 年, 徐明华小组 ${ }^{[28 a]}$ 成功将结构简单的亚磷酸 酯-烯烃配体 L19a用于铑催化的芳基嗍酸对邻二酮的不 对称 1,2-加成反应中. 在室温, $2.5 \mathrm{~mol} / \mathrm{L} \mathrm{K}_{3} \mathrm{PO}_{4}$ 水溶液 条件下, 各种芳基硼酸与邻二酮都能顺利反应, 以较高 的收率(80\% 96\% yield)和对映选择性(90\% 96\% ee) 获得目标产物. 将烯烃双键末端没有取代及取代基在双
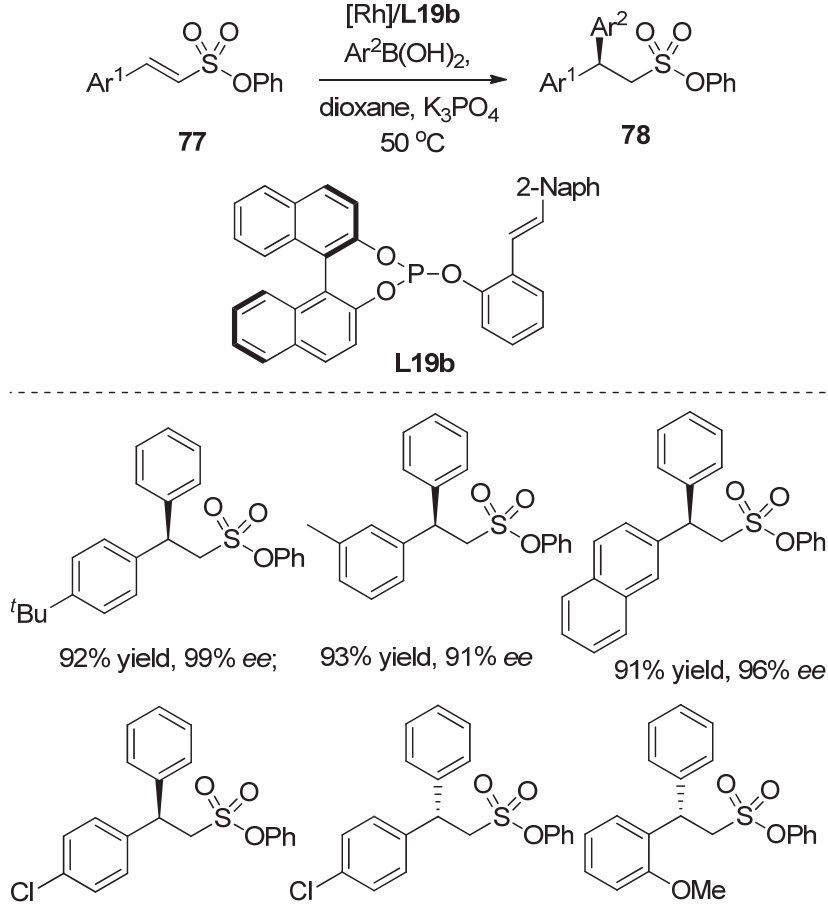

$91 \%$ yield, $93 \%$ ee

$91 \%$ yield, $93 \%$ ee $\quad 87 \%$ yield, $95 \%$ ee

图式 30 铑催化的 $\beta$-芳基- $\alpha, \beta$-不饱和磺酸酯的不对称 1,4-加成 Scheme 30 Rh-catalyzed asymmetric 1,4-addition of $\beta$-aryl- $\alpha, \beta$ unsaturated sulfonates

键内侧的配体 L19c，L19d 在同一反应中比较，发现双 键末端的取代基是反应立体选择性控制的关键; 不含双 键的配体 L19e 与 L19a 相比, 反应转化率大大降低, 产 物的 $e e$ 值不仅下降明显而且与配体 L19a 的结果相反, 这也有力地证明了双键不可或缺，虽然是开链结构，但 在反应体系中磷与烯烃均参与了和金属铑的配位，一定 程度上也说明了配体设计的合理性(如图式 31 所示).

Ready 小组 ${ }^{[14 a]}$ 报道配体 L7 同样适用于芳基硼酸对 羰基的不对称加成, 如图式 32 所示, 在 $\mathrm{Rh}(\mathrm{I})$ 催化条件 下，可以顺利得到一系列含有季碳手性中心的羟基酸酯 化合物 82，对映选择性在 $48 \%$ \% $95 \%$ 之间不等，通过制 备手性络合物单晶确认配体中的两个磷和联烯中位阻 较小的双键同时与金属中心配位，配体以三齿形式发挥 催化作用。

芳基嗍酸对醛的不对称加成极具挑战. 最近, Kamikawa 和 Ogasawara 等 ${ }^{[15 c]}$ 报道, 平面手性二羰基锰 络合物骨架的膦烯配体 $\mathbf{L 9}$ 与金属铑的配合物可以用于 催化该类反应，在苯硣酸对 1-菜醛的加成中，能够取得 $99.3 \%$ 的对映选择性，但是反应收率不太理想，仅有 $51 \%$.

2015 年, Hayashi 小组 ${ }^{[19]}$ 将膦烯配体 L11 应用到链 状酮亚胺的不对称芳基化中，首次在磷-烯配体条件下 实现了铑催化的芳基嗍酐对酮亚胺的不对称 1,2-加成. 配体在反应中表现较为理想，底物适用性广，不同电性 的芳基、杂芳基以及环状烯烃取代的亚胺和硼酐都能顺 


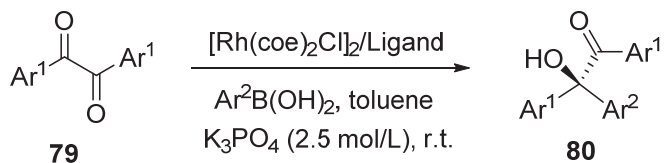

80\% 96\% yield, 90\% 96\% ee

$\mathrm{Ar}^{1}=\mathrm{Ph}, \mathrm{Ar}^{2}=4-\mathrm{MeC}_{6} \mathrm{H}_{4}$

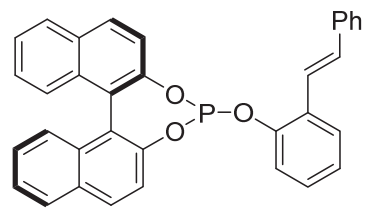

L19a $94 \%$ yield, $94 \%$ ee

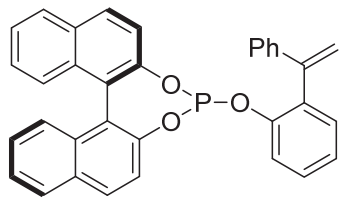

L19d $32 \%$ yield, $-46 \%$ ee

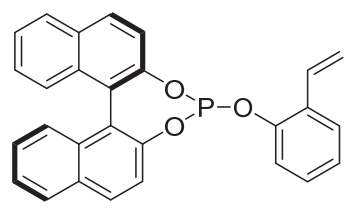

L19c $53 \%$ yield, $59 \%$ ee

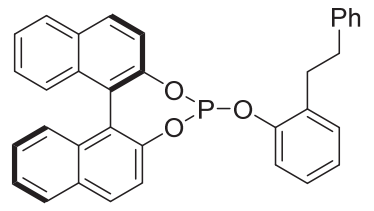

L19e $55 \%$ yield, $-3 \%$ ee
图式 31 铑催化的芳基嗍酸对邻二酮的不对称加成

Scheme 31 Rh-catalyzed asymmetric addition of arylboronic acids to $\alpha$-diketones
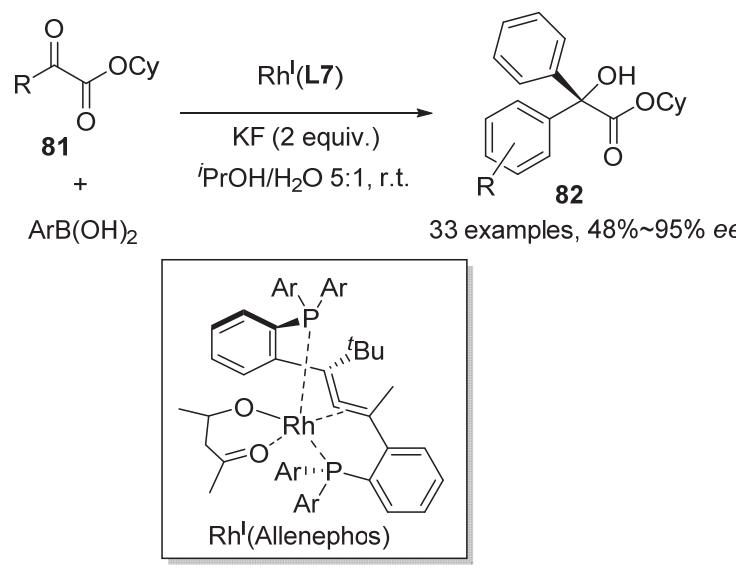

图式 $32 \mathrm{Rh} / \mathrm{L} 7$ 催化的芳基硼酸对邻二酮的不对称加成

Scheme $32 \mathrm{Rh} / \mathbf{L} 7$-catalyzed asymmetric addition of arylboronic acids to $\alpha$-diketones

利发生反应，以较高的收率得到了一系列高光学纯度的 手性仲胺 $(89 \% \sim 97 \%$ ee $)$. 值得一提的是, 含平面手性 茂金属结构的膦烯配体 L8、L9 和含有手性磷骨架的 L10a 同样适用于该反应 ${ }^{[15,18]}$, 也能取得极高的收率和 对映选择性(如图式 33 所示).

在铑催化的有机嗍试剂对环状亚胺的不对称 1,2-加 成方面, 亚磷酸酯-烯烃配体 L19 有较突出的表现 ${ }^{[28 \mathrm{a}, 28 \mathrm{c}]}$. 如图式 34 所示, 亚磷酸酯-烯烃配体 L19b 和 L19f 分别 在环状醛亚胺 85 的不对称 1,2-芳基加成和苯乙烯基加 成中给出优良的结果, 反应均可以在室温条件下顺利进 行, 底物适用范围广, 产物 $e e$ 值最高可达 $99 \%$. 值得一 提的是, 亚胺的苯乙烯基加成通常难以取得高的对映选
择性.

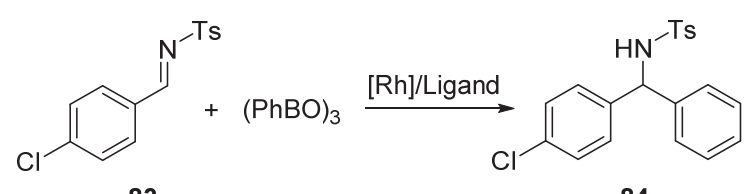

83

84<smiles>CCCCOC(=O)N1CC=CC1Cc1ccccc1</smiles>

L11

$90 \%$ yield, $97 \%$ ee

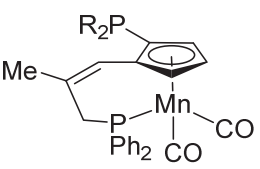

R: $3,5-\left(\mathrm{CF}_{3}\right)_{2}-\mathrm{C}_{6} \mathrm{H}_{3}$

L9

$92 \%$ yield, $99.2 \%$ ee

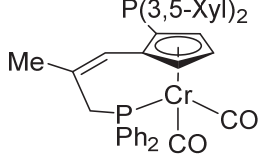

L8b<smiles>Br/C=C/CC1Oc2ccccc2P1C(Br)(Br)Br</smiles>

Ar: $3,5-\left(\mathrm{CF}_{3}\right)_{2}-\mathrm{C}_{6} \mathrm{H}_{3}$ L10a

$73 \%$ yield, $96 \%$ ee
$98 \%$ yield, $93 \%$ ee

图式 33 铑催化的芳基硼酸对亚胺的不对称加成

Scheme 33 Rh-catalyzed asymmetric addition of arylboronic acids to imines

手性 $\alpha, \alpha$-二芳基- $\alpha$-氨基酸是一类结构特殊的非天 然氨基酸, 在药物构效关系与动力学研究中非常重要, 并且是一些天然产物、药物与生物活性分子的重要结构 母核. 近期, 徐明华小组 ${ }^{[28 c]}$ 进一步发展了铑/磷-烯 (L19g)催化体系用于芳基硼酸对 1,2,5-噻二唑啉-1,1-二 氧类酮亚胺底物的不对称加成中, 在温和的反应条件 下，高效高选择性地合成了一系列含季碳手性的偕二芳 基取代的磺胺乙内酰脲以及 4-乙氧基-2,3-二氢-1,2,5-噻 唑-1,1-二氧类化合物(up to $99 \% e e$ ). 产物经 LAH一步 还原开环即可以得到 $e e$ 值保持的 $\alpha, \alpha$-二芳基- $\alpha$-氨基酸 衍生物 $\alpha, \alpha$-二芳基氨基酰胺. 利用该方法得到的产物经 简单转化还可用于各种含氮杂环的构建, 并首次实现了 Merck 公司报道的 BACE-1 抑制剂 $(R)$-iminohydantion 的 催化不对称合成(如图式 35 所示).

\section{4 不对称烯丙基取代反应}

磷-烯配体不仅在铑催化的不对称加成反应方面表 现出较理想的催化效果，这类配体同样适用于金属钯催 化的不对称烯丙基取代反应. 值得一提的是，双烯配体 在钯催化的不对称烯丙基取代反应中取得成功的报道 极少.

2005 年, Hayashi 小组 ${ }^{[30]}$ 利用配体 $\mathbf{L 2}$ 与钯形成的金 属络合物催化 1,3-二苯基烯丙基乙酯的不对称烯丙基烷 基化，可以以 $87 \%$ 的收率得到最高 $96 \% e e$ 的目标产物. 最近, 具有平面手性的膦烯配体 $\mathbf{L 8 a}{ }^{[15]}$ 和螺旋手性的膦 烯配体 $\mathbf{L 1 2}^{[21]}$ 也被成功地应用于丙二酸二甲酯对化合 物 91a 的不对称烯丙基取代中，对映选择性最高也可达 


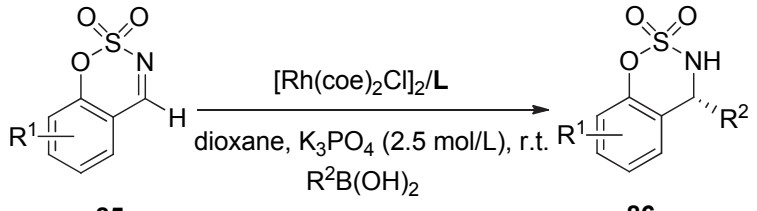

85

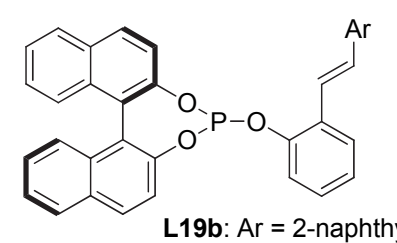

L19b: $\mathrm{Ar}=2$-naphthyl
L19f: $\mathrm{Ar}=4-\mathrm{PhC}_{6} \mathrm{H}_{4}$

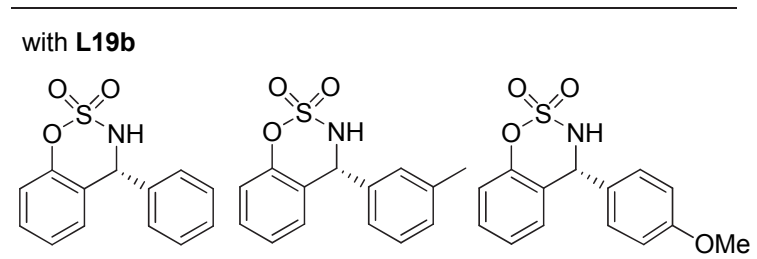

$97 \%$ yield, $98 \%$ ee $93 \%$ yield, $97 \%$ ee $94 \%$ yield, $95 \%$ ee

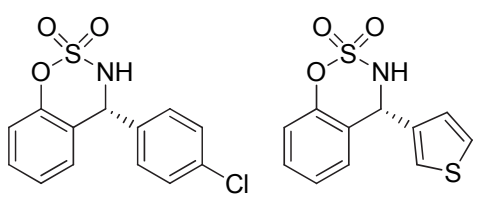

$95 \%$ yield, $97 \%$ ee $\quad 83 \%$ yield, $99 \%$ ee

(196

with L19f<smiles>O=S1(=O)NC(=Cc2ccccc2)c2ccccc2O1</smiles><smiles>Cc1cccc2c1OS(=O)(=O)N/C2=C\c1ccccc1</smiles>

$87 \%$ yield, $92 \%$ ee

$89 \%$ yield, $94 \%$ ee<smiles>Cc1ccc2c(c1)C(/C=C/c1ccccc1)NS(=O)(=O)O2</smiles><smiles>COc1ccc2c(c1)OS(=O)(=O)N/C2=C\c1ccccc1</smiles>

$92 \%$ yield, $93 \%$ ee

$64 \%$ yield, $91 \%$ ee

图式 34 铑催化的环状亚胺 $\mathbf{8 5}$ 的不对称芳基化

Scheme 34 Rh-catalyzed asymmetric arylation of cyclic imine $\mathbf{8 5}$

94\%. 而亚膦酸酯-烯烃配体 L18 虽然可以顺利催化反 应, 但立体选择性并不理想, ee 值仅为 $61 \%{ }^{[27]}$. 有意思 的是, 杜海峰小组 ${ }^{[11]}$ 发展的酒石酸酯衍生的简单膦烯 配体 L5a 在该类反应中表现出色, 可以催化底物与丙二 酸二甲酯、取代丙二酸酯、芐醇、吗啉等多种类型的亲 核试剂的反应，并且取得较高的收率(86\% 99\%)和优 秀的对映选择性 $(90 \% \sim 99 \% e e$ )(如图式 36 所示).

此外, 杜海峰小组 ${ }^{[13 a]}$ 还将配体 $\mathbf{L 6}$ 用于钯催化的吲 哚对烯丙基乙酸酯的不对称烯丙基取代反应. 除吲哚以 外, 这类配体在吡咯、4,7-二氢吲哚和肟做亲核试剂的
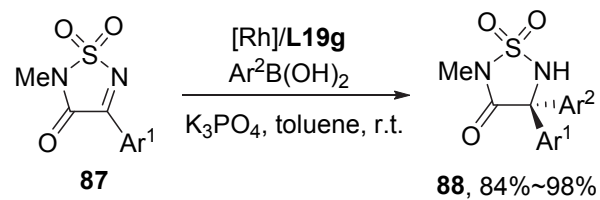

88, $84 \% \sim 98 \%$ ee
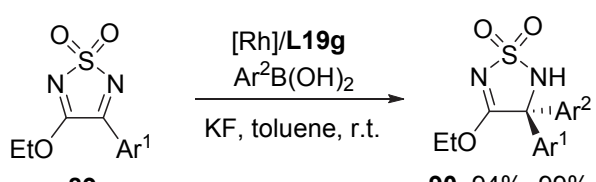

89

90, $94 \% \sim 99 \%$ ee<smiles>[Al]C=Cc1ccccc1Op1oc2ccc3c(c2c2c4c(ccc2o1)CCCC4)CCCC3</smiles>

$\mathrm{Ar}=4-{ }^{t} \mathrm{BuC}_{6} \mathrm{H}_{4}$

L19g
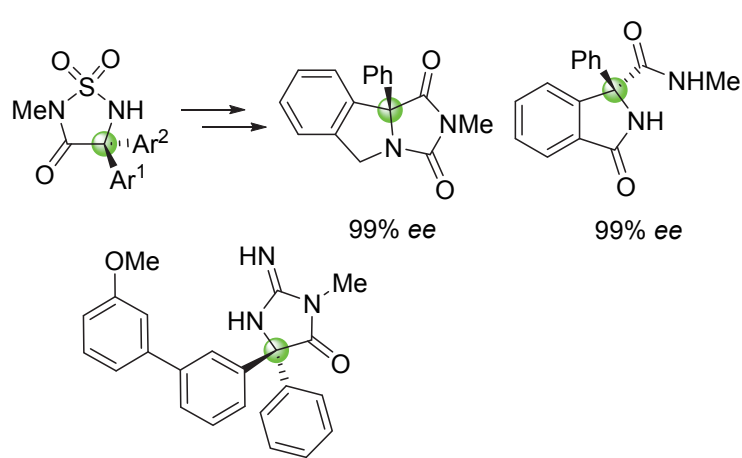

$(R)$-iminohydantoin

图式 35 铑催化的环状亚胺 87 和 89 的不对称芳基化

Scheme 35 Rh-catalyzed asymmetric arylation of cyclic imines 87 and 89

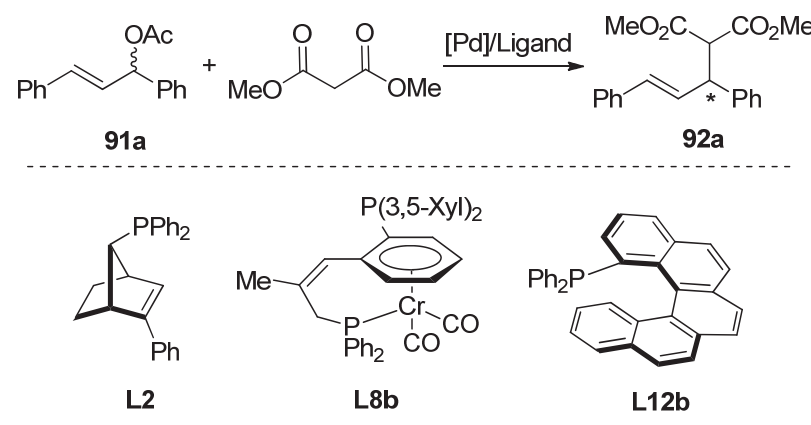

$87 \%$ yield, $96 \%$ ee $\quad 68 \%$ yield, $94 \%$ ee $\quad 99 \%$ yield, $94 \%$ ee

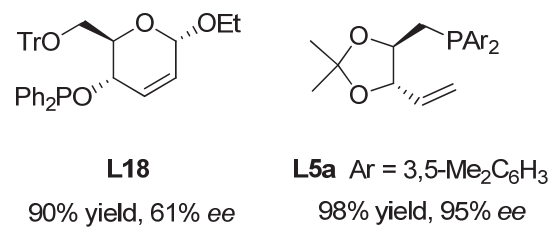

图式 36 钯催化的不对称烯丙基烷基化

Scheme 36 Pd-catalyzed asymmetric allylic alkylation

烯丙基取代反应中，也有优秀的表现，以较好的收率和 中等到优秀的对映选择性得到目标产物(如图式 37 所示). 


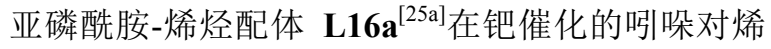
丙基醋酸酯的不对称烯丙基取代反应中，以及脂肪胺的 不对称烯丙基胺化反应中也有优秀的表现, 对映选择性 相较配体 L6 有了明显的改善. 当使用盐酸羟胺做氮源 时，反应也能顺利进行，并且得到了 $95 \%$ 的对映选择性. 以 BINOL 骨架 3,3'无取代的 L16b 为手性配体时 ${ }^{[25 b]}$, 大 位阻的 3-取代吲哚同样可以对底物 91 进行不对称烯丙 基取代，对映选择性在 34\% 87\%之间(如图式 38 所示). 最近该小组在钯-L16a 条件下, 以靛红衍生物为氮源, 实现了环氧丁烯的不对称烯丙基位的氨化反应 ${ }^{[25 \mathrm{~d}]}$, 收 率良好, 区域选择性在 $10 / 1 \sim>20 / 1$ 之间, ee 值在 $80 \% \sim 97 \%$ 之间.

Mino 等 ${ }^{[22]}$ 报道的具有轴手性的膦烯配体 L13 和 Usui 等 ${ }^{[21]}$ 报道的具有螺旋手性的膦烯配体 L12a 同样可 以催化吲哚对烯丙基乙酸酯进行不对称烯丙基化取代

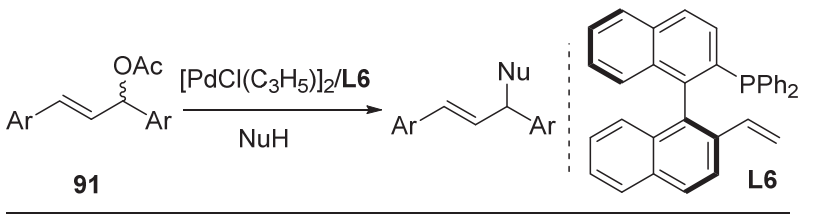

$$
\text { ar }
$$

$72 \% \sim 99 \%$ yield $75 \%$ 94\% ee<smiles>[R]c1cc[nH]c1C(/C=C/c1ccccc1)c1ccccc1</smiles>

64\% 97\% yield $81 \% \sim 97 \%$ ee<smiles>[R]C1=CCC2=C(C1)CC(C(/C=C/c1ccccc1)c1ccccc1)=C2</smiles><smiles>[R]C([R])=NOC(Br)/C=C/[Bi]</smiles>

$54 \% \sim 99 \%$ yield $83 \% \sim 96 \%$ ee
图式 $37 \mathrm{Pd} / \mathbf{L 6}$ 催化的不对称烯丙基取代反应

Scheme $37 \mathrm{Pd} / \mathbf{L 6}$-catalyzed asymmetric allylic substitution reactions<smiles>[R]C=CC([R2])OC(C)(C)CCCCCCCC([R])N</smiles>

91

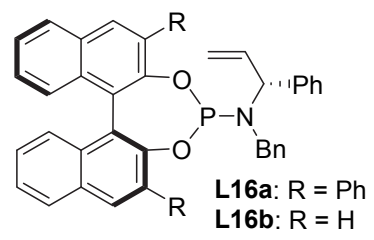

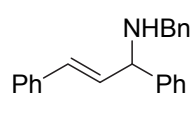

$95 \%$ yield, $94 \%$ ee<smiles>ONC(/C=C/c1ccccc1)c1ccccc1</smiles>

$70 \%$ yield, $95 \%$ ee

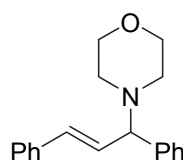

$97 \%$ yield, $93 \%$ ee<smiles>[R]C=CCC1([R])C=Nc2c[R]#ccc21</smiles>

76\% 97\% yield, $34 \% \sim 87 \%$ ee
图式 $38 \mathrm{Pd} / \mathbf{L} 16$ 催化的不对称烯丙基胺化

Scheme $38 \mathrm{Pd} /$ L16-catalyzed asymmetric allylic amination
反应，得到一系列 $e e$ 值在 $57 \% \sim 99 \%$ 的 3-取代吲哚. 其 中, L12a 表现出极佳的催化活性, 反应可以在室温进行, 而且收率几乎定量，对映选择性均在 96\% 99\%. L12a 还被成功用于各种醇对烯丙基乙酸酯的不对称烯丙基 醚化反应中(如图式 39 所示).<smiles>[R]c1ccc2[nH]cc(C(/C=C\c3ccccc3)c3ccccc3)c2c1</smiles>

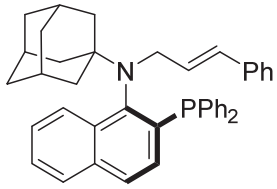

(R)-L13

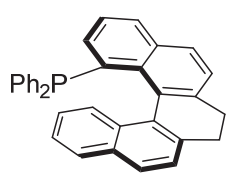

L12a
$60 \% \sim 82 \%$ yield, $57 \% \sim 97 \%$ ee $\quad 95 \% \sim 99 \%$ yield, $96 \% \sim 99 \%$ ee

$$
\begin{aligned}
& \sum_{\mathrm{Ph}}^{\mathrm{OAc}}+\mathrm{ROH} \frac{\left[\mathrm{PdCl}\left(\mathrm{C}_{3} \mathrm{H}_{5}\right)\right]_{2} / \mathrm{L12a}}{\mathrm{Cs}_{2} \mathrm{CO}_{3}, \mathrm{CH}_{2} \mathrm{Cl}_{2} \text {, r.t. }} \mathrm{Ph}_{\mathrm{Ph}}^{\mathrm{OR}} \\
& \text { 91a } \\
& \mathrm{R}=\mathrm{Me}, \mathrm{Et}, \mathrm{Bn} \text {, allyl, furfuryl } \quad 61 \% \sim 95 \% \text { yield, } \\
& 84 \% \text { 96\% ee }
\end{aligned}
$$

图式 39 钯催化的不对称烯丙基取代反应

Scheme 39 Pd-catalyzed asymmetric allylic substitution reactions

在不对称烯丙基取代反应中，除了钯催化，铱催化 也取得了很大的成功. 2007 年, Carreira 等 ${ }^{[24 a]}$ 以氨基磺 酸作为氮源, 利用亚磷酰胺-烯烃配体 L15a 实现了铱催 化的烯丙醇的直接氨基化反应，虽然只取得了中等的对 映选择性 $(70 \% e e)$, 但这是首例由烯丙醇直接制备烯丙 基胺的报道, 具有重要意义. 在此基础之上, Carreira 小 组 ${ }^{[24 \mathrm{~b}]}$ 对反应条件进行进一步优化, 将体系拓展到不同 类型烯丙醇底物的不对称氨基化中，反应对映选择性最 高可达 99\%, 产物通过一步转化可以得到二取代烯丙 胺. 此外, 在 Ir/L15a 催化体系下, 醇, 硫醇, 烯基氟硣 酸钾, 炔基氟嗍酸钾以及简单的末端烯烃等亲核试剂也 能够与烯丙醇直接进行不对称烯丙基取代反应，以较高 的区域选择性以及对映选择性得到相应的手性化合物 (如图式 40 所示) ${ }^{[24 c \sim 24 g]}$.

2012 年, Carreira 小组 ${ }^{[31 a]}$ 在手性配体 L15a 条件下 首次实现了铱催化的多烯环化反应，该反应通过 Lewis 酸催化对烯丙醇进行活化，形成烯丙基钯中间体后进行 不对称烯丙基取代得到多环化产物，反应立体控制非常 理想, ee 值均可以达到 $99 \%$ 以上(如图式 41 所示). 基于 该策略, 又成功实现了天然产物 $(+)$-Asperolide 的不对 称全合成 ${ }^{[31 b]}$.

2013 年, Carreira 小组 ${ }^{[32 a]}$ 又将手性磷烯配体 L15a 与金鸡纳生物碱衍生物 97 结合，通过共催化的策略实 现了支链醛的 $\alpha$-烯丙基化反应. 反应底物适用性广，以 中等到良好的收率和优秀的立体控制得到了一系列含 


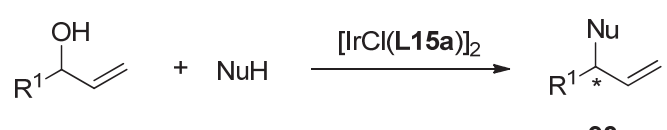

92

93

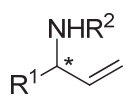

$48 \% \sim 87 \%$ yield $\quad 36 \% \sim 99 \%$ yield $79 \% \sim 92 \%$ yield $68 \% \sim 99 \%$ ee $\quad 63 \% \sim 99 \%$ ee $\quad 90 \% \sim 97 \%$ ee<smiles>[R]C#CC([R1])C=C</smiles><smiles>[R]C([R])=C([R])C=C</smiles><smiles>[R]C(C=C)CC1=CCCCC1</smiles>

$51 \% \sim 99 \%$ yield $51 \% \sim 99 \%$ yield $51 \% \sim 85 \%$ yield 95\% >99\% ee $\quad 89 \% \sim 99 \%$ ee $\quad 98 \% \sim 99 \%$ ee

图式 $40 \mathrm{Ir} / \mathrm{L15}$ 催化的烯丙醇 92 的不对称取代

Scheme $40 \quad$ Ir/L15-catalyzed asymmetric allylic substitution of $\mathbf{9 2}$

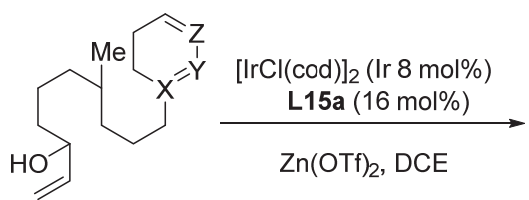

94

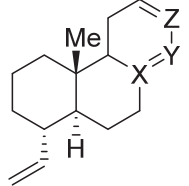

95
$69 \% \sim 93 \%$ yield, $>99 \%$ ee<smiles>C1=Cc2ccccc2N(p2oc3ccc4ccccc4c3c3c(ccc4ccccc43)o2)c2ccccc21</smiles>

L15a

图式 41 铱催化的不对称多烯环化反应

Scheme 41 Ir-catalyzed enantioselective polyene cyclization

有连续两个手性中心的产物. 在相同的原料下, 通过手 性磷-烯配体和手性胺的不同组合和催化调控，实现了 反应的各向立体控制(Divergent stereocontrol), 可以在 获得产物高对映选择性的同时, 以相异的非对映选择性 得到所有的立体异构体(如图式 42 所示).

此外, 利用同样的策略, Carreira 小组 ${ }^{[32 b]}$ 于 2014 年 又进一步实现了链状醛与烯丙基醇的 $\alpha$-位烯丙基取代 反应, 以理想的非对映选择性和高于 $99 \%$ 的对映选择性 得到含有两个手性中心的 $\gamma, \delta$-不饱和醛(如图式 43 所示).

\section{5 不对称分子内加氢酰化}

2011 年, Carreira 小组 ${ }^{[33]}$ 用手性螺环骨架替代配体 L15a 中的 1,1'-联菜骨架, 合成了新配体 L15b, 其与金 属铑形成的络合物可以顺利催化成-4-烯醛的分子内加 氢酰化反应，合成了一系列手性环戊酮类化合物. 反应 的对映选择性受底物影响, ee 值在 $80 \% \sim 97 \%$ 之间不等 (如图式 44 所示).

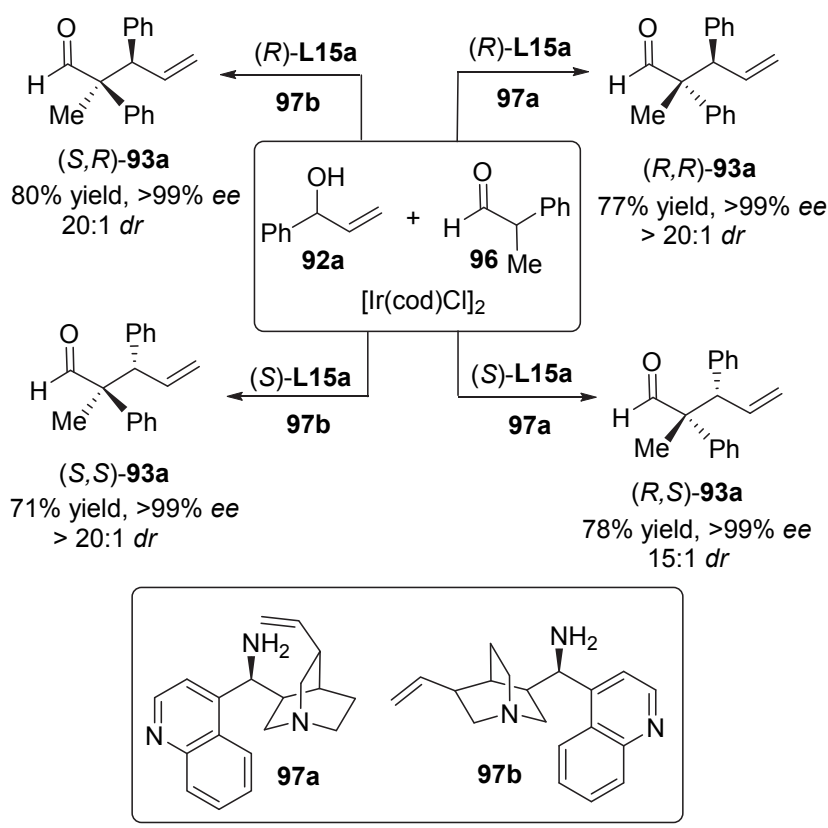

图式 42 支链醛的 $\alpha$-位不对称烯丙基化

Scheme 42 Enantioselective $\alpha$-allylation of branched aldehydes

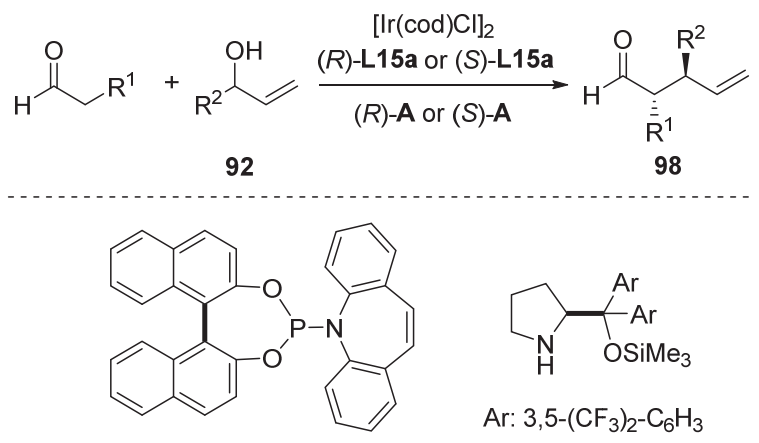

$(R)-\mathbf{L} 15 \mathbf{a}$ or $(S)-\mathbf{L} 15 \mathbf{a}$

$(R)-\mathbf{A}$ or $(S)-\mathbf{A}$

图式 43 链状醛的 $\alpha$-位不对称烯丙基化

Scheme 43 Enantioselective $\alpha$-allylation of linear aldehydes

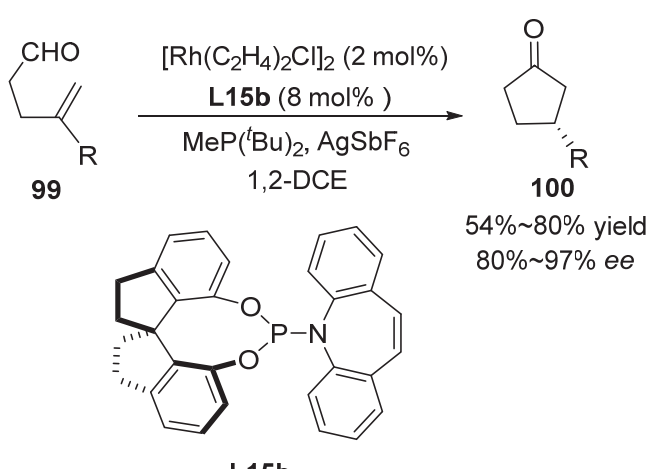

L15b

图式 $44 \mathrm{Rh} / \mathbf{L 1 5 b}$ 催化的不对称分子内加氢酰化

Scheme $44 \mathrm{Rh} / \mathbf{L} 15 \mathrm{~b}$-catalyzed asymmetric intramolecular hydroacylation

\section{6 不对称 Suzuki-Miyaura 偶联反应}

要实现不对称 Suzuki-Miyaura 偶联反应是非常挑战 
的, 最近, Suemune 和 Usui 等 ${ }^{[21]}$ 利用具有 [5]螺烯母核的 膦烯配体 L12b 实现了温和条件下 1-溴萘基磷酸酯 101 与邻位取代的苯嗍酸 102 的高效偶联, 得到了一系列具 有轴手性的联芳基化合物 103, 对映选择性最高可达到 99\%. 当配体母核为 7,8-二氢[5]螺烯(L12a)时, 反应依 然可以顺利进行, 但收率和对映选择性都明显下降(如 图式 45 所示). 对两个配体在反应中的过渡态能垒进行 DFT 计算, 结果发现当配体中母核为[5]螺烯时, 由于分 子在空间上的螺旋角度略小, 使得整个芳香体系更容易 和金属钯有相互作用，从而更有利于立体选择性.

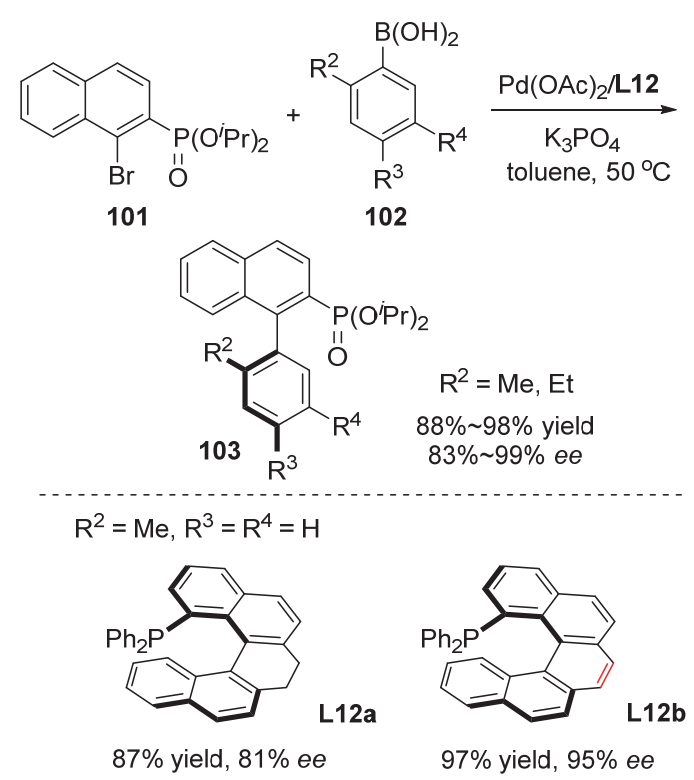

图式 $45 \mathrm{Pd} / \mathbf{L} 12$ 催化的不对称 Suzuki-Miyaura 偶联反应

Scheme $45 \mathrm{Pd} / \mathbf{L} 12$-catalyzed asymmetric Suzuki-Miyaura coupling

\section{4 总结与展望}

手性磷-烯配体在不对称催化反应中的应用近年来 受到化学家们的关注, 已经成为一个热门的研究领域, 一大批优秀的工作相继涌现, 取得了不错的进展. 磷原 子与金属较强的配位能力也确实给磷-烯配体带来了与 双烯配体不一样的反应机会, 由于兼具了部分手性膦配 体和双烯配体的优点, 在一些过渡金属如铑、钯、铱等 催化的不对称反应中表现出与传统的手性双烯配体及 手性双膦配体不同的独特的催化性能, 尤其在钯催化的 不对称烯丙基取代反应中, 不但能高效催化反应, 而且 能取得优异的对映选择性, 这些研究开启了手性烯烃配 体在不对称催化领域的一个新篇章. 但综合已有的工 作，我们也不难发现，与传统的手性磷、氮等配体相比， 磷-烯配体的应用范围仍然相对较窄，反应类型还较少， 配位金属种类局限, 尤其是在铁、钴、镍等廉价金属催 化领域还没有取得突破; 此外, 许多磷-烯配体含有复 杂的碳手性骨架, 结构并不简单, 因此合成也不容易; 所以设计结构更加简单、催化性能优异的新型磷-烯配 体和其它杂化烯烃配体如硫-烯、氮-烯等并对其应用范
围进行拓展仍是意义重大的研究课题, 必将吸引人们对 此进行更广泛的研究.

\section{作者简介}

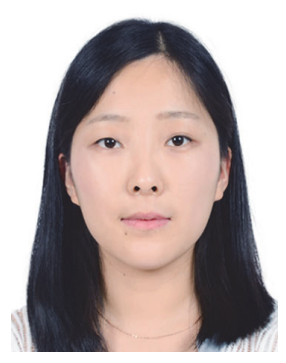

于月娜, 2010 年于山东师范大学获得学士学位后进入中 国科学院上海药物研究所学习, 导师徐明华研究员, 2015 年 6 月获理学博士学位, 目前在南方科技大学从事博士后工作研 究. 主要从事手性配体的设计、合成与催化不对称应用研究.

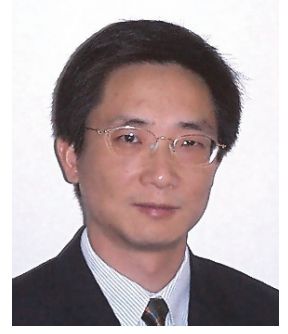

徐明华, 中国科学院上海药物研究所, 新药研究国家重 点实验室研究员, 课题组长, 博士生导师。中国科学院 “百人 计划”、国家杰出青年基金获得者, 上海市优秀学术带头人, 中国科学院特聘研究员(骨千). 博士毕业于中国科学院上海有 机化学研究所, 曾先后在美国弗吉尼亚大学化学系和乔治城 大学医学研究中心从事博士后工作研究. 主要从事有机不对 称合成及手性药物方面的研究, 致力于以一些重要有机分子 及药物分子合成为导向的手性化学和手性技术探索. 2014 年 获上海市自然科学一等奖, 2016 年获国家自然科学二等奖.

\section{References}

[1] (a) Zhou, Q.-L. Privileged Chiral Ligands and Catalysts, Wiley-VCH, 2011. (b) Seyden-Penne, J. Chiral Auxiliaries and Ligands in Asymmetric Synthesis, Wiley-Interscience, 1995. (c) Ding, K. Acta Chim. Sinica 2014, 72, 755 (in Chinese). (丁奎岭, 化学学 报, 2014, 72, 755.) (d) Xie, J.; Zhou, Q.-L. Acta Chim. Sinica 2014, 72, 778 (in Chinese). (谢建华, 周其林，化学学报，2014，72，778.) (e) Zhao, W.; Yang, D.; Zhang, Y. Chin. J. Org. Chem. 2016, 36, 2301 (in Chinese). (赵文献, 杨代月, 张玉华, 有机化学, 2016, 36, 2301.) (f) Yuan, Q.; Zhang, W. Chin. J. Org. Chem. 2016, 36, 274 (in Chinese). (袁乾家, 张方斌, 有机化学, 2016, 36, 274.)

[2] Zeise, W. C. Poggendorff's Ann. Phys. 1827, 9, 632.

[3] Hayashi, T.; Ueyama, K.; Tokunaga, N.; Yoshida, K. J. Am. Chem. Soc. 2003, 125, 11508 .

[4] Fisher, C.; Defieber, C.; Suzuki, T.; Carreira, E. M. J. Am. Chem. Soc. 2004, 126, 1628

[5] For reviews, see: (a) Glorius, F. Angew. Chem. Int. Ed. 2004, 43, 3364. (b) Johnson, J. B.; Rovis, T. Angew. Chem. Int. Ed. 2008, 47 , 840. (c) Defieber, C.; Grützmacher, H.; Carreira, E. M. Angew. Chem. Int. Ed. 2008, 47, 4482. (d) Shintani, R.; Hayashi, T. Aldrichim. Acta 2009, 42, 31. (e) Feng, C.-G.; Xu, M.-H.; Lin, G.-Q. Synlett 2011, 10, 1345. (f) Feng, X.; Du, H. Asian J. Org. Chem. 2012, 1, 204. (g) Li, Y.; Xu, M.-H. Chem. Commun. 2014, 50, 3771. (h) Feng, X. Q.; Du, H. F. Chin. J. Org. Chem. 2015, 35, 259 (in Chinese). (冯向青, 杜海峰, 有机化学, 2015, 35, 259.)

[6] (a) Maire, P.; Deblon, S.; Breher, F.; Geier, J.; Böhler, C.; Rügger, 
H.; Schönberg, H.; Grützmacher, H. Chem. Eur. J. 2004, 10, 4198. (b) Thoumazet, C.; Ricard, L.; Grützmacher, H.; Floch, F. P. Chem. Commun. 2005, 41, 1592.

[7] Piras, E.; Läng, F.; Rüegger, H.; Stein, D.; Wörle, M.; Grützmacher, H. Chem. Eur. J. 2006, 12, 5849 .

[8] (a) Shintani, R.; Duan, W.-L.; Nagano, T.; Okada, A.; Hayashi, T. Angew. Chem. Int. Ed. 2005, 44, 4611. (b) Duan, W.; Iwamura, H.; Shintani, R.; Hayashi, T. J. Am. Chem. Soc. 2007, 129, 2130.

[9] Kasák, P.; Arion, V. B.; Widhalm, M. Tetrahedron Asymmetry 2006, 17,3084 .

[10] (a) Štěpnička, P.; Císařová, I. Inorg. Chem. 2006, 45, 8785. (b) Stemmler, R, T.; Bolm, C. Synlett 2007, 9, 1365. (c) Csizmadiová, J.; Mečiarová, M.; Rakovský, E.; Horváth, B.; Šebesta, R. Eur. J. Org. Chem. 2011, 6110.

[11] Liu, Z.; Du, H. Org. Lett. 2010, 12, 3054

[12] (a) Wershofen, S.; Scharf, H.-G. Synthesis 1988, 854. (b) Bell, T. W.; Ciaccio, J. A. J. Org. Chem. 1993, 58, 5153. (c) Mukai, C.; Kim, J. S.; Sonobe, H.; Hanaoka, M. J. Org. Chem. 1999, 64, 6822. (d) Pandey, G.; Kapur, M. Org. Lett. 2002, 4, 3883. (e) Pandey, G.; Kapur, M.; Khan, M. I.; Gaikwad, S. M. Org. Biomol. Chem. 2003, 1, 3321. (f) Horváth, A.; Benner, J.; Bäckvall, J.-E. Eur. J. Org. Chem. 2004, 3240.

[13] (a) Cao, Z.; Liu, Y.; Liu, Z.; Feng, X.; Zhuang, M.; Du, H. Org. Lett. 2011, 13, 2164. (b) Cao, Z.; Liu, Z.; Liu, Y.; Du, H. J. Org. Chem. 2011, 76, 6401. (c) Liu, Y.; Cao, Z.; Du, H. J. Org. Chem. 2012, 77, 4479 .

[14] (a) Cai, F.; Pu, X.; Qi, X.; Lynch, V.; Radha, A.; Ready, J. M. J. Am. Chem. Soc. 2011, 133, 18066. (b) Antczak, M. I.; Cai, F.; Ready, J. M. Org. Lett. 2011, 13, 184.

[15] (a) Ogasawara, M.; Wu, W.-Y.; Arae, S.; Watanabe, S.; Morita, T.; Takahashi, T.; Kamikawa, K. Angew. Chem. Int. Ed. 2012, 51, 2951. (b) Ogasawara, M.; Tseng, Y. Y.; Arae, S.; Morita, T.; Nakaya, T.; Wu, W. Y.; Takahashi, T.; Kamikawa, K. J. Am. Chem. Soc. 2014, 136, 9377. (c) Kamikawa, K.; Tseng, Y.-Y.; Jian, J.-H.; Takahashi, T.; Ogasawara, M. J. Am. Chem. Soc. 2017, 139, 1545.

[16] (a) Alexakis, A.; Kanger, T.; Mangeney, P.; Rose-Munch, F.; Perrotey, A.; Rose, E. Tetrahedron: Asymmetry 1995, 6, 47. (b) Taniguchi, N.; Uemura, M. Tetrahedron 1998, 54, 12775.

[17] (a) Ferber, B.; Top, S.; Jaouen, G. J. Organomet. Chem. 2004, 689, 4872. The chiral acetal directing group was originally introduced by Kagan for the preparation of planar-chiral ferrocene derivatives, see: (b) Riant, O.; Samuel, O.; Kagan, H. B. J. Am. Chem. Soc. 1993, 115, 5835. (c) Riant, O.; Samuel, O.; Flessner, T.; Taudien, S.; Kagan, H. B. J. Org. Chem. 1997, 62, 6733. (d) Geisler, F. M.; Helmchen, G. Synthesis 2006, 2201. (e) Wölfle, H.; Kopacka, H.; Wurst, K.; Ongania, K.-H.; Görtz, H.-H.; Preishuber-Pflügl, P.; Bildstein, B.
J. Organomet. Chem. 2006, 691, 1197.

[18] Sieber, J. D.; Chennamadhavuni, D.; Fandrick, K. R.; Qu, B.; Han, Z. S.; Savoie, J. Org. Lett. 2014, 16, 5494

[19] Gandi, V. R.; Lu, Y.; Hayashi, T. Tetrahedron: Asymmetry 2015, 26, 679.

[20] Qiu, X.-L.; Qing, F.-L. J. Org. Chem. 2005, 70, 3826.

[21] Yamamoto, K.; Shimizu, T.; Igawa, K.; Tomooka, K.; Hirai, G.; Suemune, H.; Usui, K. Sci. Rep. 2016, 6, 36211.

[22] Mino, T.; Nishikawa, K.; Asano, M.; Shima, Y.; Ebisawa, T.; Yoshidaa, Y.; Sakamotoa, M. Org. Biomol. Chem. 2016, 14, 7509.

[23] Shintani, R.; Narui, Y.; Hayashi, S.; Hayashi, T. Chem. Commun. 2011, 47, 6123 .

[24] (a) Defieber, C.; Ariger, M. A.; Moriel, P.; Carreira, E. M. Angew. Chem. Int. Ed. 2007, 46, 3139. (b) Lafrance, M.; Roggen, M.; Carreira, E. M. Angew. Chem. Int. Ed. 2012, 51, 3470. (c) Roggen, M. Carreira, E. M. Angew. Chem. Int. Ed. 2011, 50, 5568. (d) Roggen, M.; Carreira, E. M. Angew. Chem. Int. Ed. 2012, 51, 8652. (e) Hamilton, J. Y.; Sarlah, D.; Carreira, E. M. Angew. Chem. Int. Ed. 2013 52, 7532. (f) Hamilton, J. Y.; Sarlah, D.; Carreira, E. M. J. Am. Chem. Soc. 2013, 135, 994. (g) Hamilton, J. Y.; Sarlah, D.; Carreira, E. M. J. Am. Chem. Soc. 2014, 136, 3006.

[25] (a) Liu, Z.; Cao, Z.; Du, H. Org. Biomol. Chem. 2011, 9, 5369. (b) Liu, Y.; Du, H. Org. Lett. 2013, 4, 740. (c) Liu, Y.; Feng, X.; Du, H. Org. Biomol. Chem. 2015, 13, 125. (d) Li, G.; Feng, X.; Du, H. Org. Biomol. Chem. 2015, 13, 5826.

[26] Chen, Q.; Li, L.; Zhou, G.; Ma, X.; Zhang, L.; Guo, F.; Luo, Y.; Xia, W. Chem. Asian J. 2016, 11,1518 .

[27] Minuth, T.; Boysen, M. M. K. Org. Lett. 2009, 11, 4212.

[28] (a) Yu, Y.-N.; Xu, M.-H. Org. Chem. Front. 2014, 1, 738. (b) Yu, Y.-N.; Xu, M.-H. Acta Chim. Sinica 2014, 72, 815 (in Chinese). (于 月娜, 徐明华, 化学学报, 2014, 72, 815.) (c) Li, Y.; Yu, Y.-N.; Xu, M.-H. ACS Catal. 2016, 6, 661.

[29] (a) Mariz, R.; Briceño, A.; Dorta, R. Organometallics 2008, 27, 6605. (b) Drinkel, E.; Briceño, A.; Dorta, R. Organometallics 2010, 29,2503

[30] Shintani, R.; Duan, W.-L.; Okamoto, K.; Hayashi, T. Tetrahedron: Asymmetry 2005, 16, 3400 .

[31] (a) Schafroth, M. A.; Sarlah, D.; Krautwald, S.; Carreira, E. M. J. Am. Chem. Soc. 2012, 134, 20276. (b) Jeker, O. F.; Kravina, A. G.; Carreira, E. M. Angew. Chem. Int. Ed. 2013, 52, 12166.

[32] (a) Krautwald, S.; Sarlah, D.; Schafroth, M. A.; Carreira, E. M. Science 2013, 340, 1065. (b) Krautwald, S.; Schafroth, M. A.; Sarlah, D.; Carreira, E. M. J. Am. Chem. Soc. 2014, 136, 3020.

[33] Hoffman, T. J.; Carreira, E. M. Angew. Chem. Int. Ed. 2011, 50, 10670 .

(Cheng, B.) 